Article

\title{
Quantification of Efficiency Improvements from Integration of Battery Energy Storage Systems and Renewable Energy Sources into Domestic Distribution Networks
}

\author{
Mohamed E. A. Farrag ${ }^{1,2, * \mathbb{C}}$, Donald M Hepburn ${ }^{1}$ and Belen Garcia ${ }^{3}$ \\ 1 School of Engineering and Built Environment, Glasgow Caledonian University, Glasgow G4 0BA, UK; \\ dmhepburn_gcu@yahoo.com \\ 2 Faculty of Industrial Education, Helwan University, 11795 Helwan, Egypt \\ 3 Electrical Engineering Department, Universidad Carlos III de Madrid, 28911 Madrid, Spain; \\ belen.garcia@uc3m.es \\ * Correspondence: Mohamed.Farrag@gcu.ac.uk
}

Received: 30 October 2019; Accepted: 5 December 2019; Published: 6 December 2019

\begin{abstract}
Due to the increasing use of renewable, non-controllable energy generation systems energy storage systems (ESS) are seen as a necessary part of future power delivery systems. ESS have gained research interest and practical implementation over the past decade and this is expected to continue into the future. This is due to the economic and operational benefits for both network operators and customers, battery energy storage system (BESS) is used as the main focus of this research paper. This paper presents an analytical study of the benefits of deploying distributed BESS in an electrical distribution network (DN). The work explores the optimum location of installing BESS and its impact on the DN performance and possible future investment. This study provides a comparison between bulk energy storage installed at three different locations; medium voltage (MV) side and low voltage (LV) side of the distribution transformer (DT) and distributed energy storage at customers' feeders. The performance of a typical UK DN is examined under different penetration levels of wind energy generation units and BESS. The results show that the minimum storage size is obtained when BESS is installed next to the DT. However, the power loss is reduced to its minimum when BESS and wind energy are both distributed at load busbars. The study demonstrates that BESS installation has improved the loss of life factor of the distribution transformer.
\end{abstract}

Keywords: energy storage systems; renewable sources; distribution network operation; distribution losses

\section{Introduction}

The traditional electricity market had to deal with challenges in supply-demand balance, but the introduction of renewable energy sources has resulted in a market need for energy storage systems. The traditional view has been that electricity should be consumed at the same instant that it is generated, i.e., the amount of electricity generated must always match the load demand. Any imbalance between generation and consumption will damage the stability and quality of the electrical supply grid parameters [1]. Although electrochemical storage elements, e.g., batteries, have played vital roles in everyday applications for many decades, the power demand has tended to be at low levels. For power plants and substations, batteries are used as a reliable power source for the operation of switchgear, critical standby systems and possibly black start of stations [2]. In more recent times, due to the variability of generation of electricity from wind, solar, etc., the need for larger-scale storage of energy has developed. Grid-scale battery storage units have recently shown an improvement in both 
technology and cost that allows them to be used for constant power supply and allows electricity generated from alternative sources/renewables to be stored in large amounts [3].

Energy storage systems (ESS) can benefit electricity transmission and distribution systems, i.e., they can be used to mitigate variations in electrical load and in energy generated from renewable sources to ensure energy produced is used more efficiently [4,5]. ESS can perform well in meeting power demand or reducing demand peaks. This, in turn, may reduce challenges in load scheduling and generation capacity would only be required to meet the average demand rather than the peak and its security margin [6]. Incentives and other encouragements to get the general population to alter their use of electrical loads from peak time to off-peak times are not receiving wide public support, therefore, other approaches have been investigated by researchers e.g., load shaving. In this approach, battery ESS (BESS) are integrated into the conventional distribution network (DN) to be charged during the off-peak times and discharge during the peak times, hence, domestic loads are running as customers request while energy cost savings are still achievable [7].

Energy storage has been introduced in [8] to allow users to benefit from the energy price variations, where ESS owners buy energy during off-peak times (low price) and then use stored energy to satisfy their demand when energy prices are high, however, this research did not offer robust control mechanisms that can be followed by individuals. ESS has been recommended to control the prosumer market for economic and stable grid operation [9].

ESS has been used to support the control of network frequency under disturbance scenarios and the penetration of renewable sources $[10,11]$. In $[12,13]$, ESS and supercapacitor have been used as a power source to maintain the voltage and frequency stability of an autonomous microgrid. These researches used droop control merged with BESS state of charge to fine-tune the system frequency variation, however, it did not study the impact of BESS locations or system losses.

In [14] the trade-off between the flexibility of future grid operation and challenges of integrating ESS into the grid, attributed to case dependent power electronics interfaces, was discussed. While the impact of ESS on reducing transmission and distribution systems losses was introduced in [15], the authors did not consider the influence of distributed generation (DG) on the losses or ESS sizing. Although [16] investigates the effect of location of bulk BESS on either side of a distribution transformer (DT), the impact of distribution of BESS across a DN is not considered. The use of ESS to support the operation of renewable energy sources, e.g., wind energy, by storing the excess energy at times where wind energy production outstrips demand is addressed in [17]. Optimum location of DG for loss reduction and voltage profile enhancement in a DN is presented in [18], however, this did not consider loss reduction possibilities through the integration of DG and ESS.

Authors of [19] have studied the interactions between ESS location, penetration and the investment decisions in transmission system, their results show that ESS is a substitute and complement of transmission assets. State of energy has been used in [20-22] to optimise the size of the ESS in an active distribution network to keep the power balance using continuous function compared to discrete function, the articles did not consider the impacts of BESS location. Energy transaction cost is optimised in [23] through a short term load forecasting and renewable source forecasting.

In the research presented here, the impacts of BESS on DN system losses are investigated, considering bulk storage and storage at distributed locations through the DN and also using installation of renewable sources. The losses in the distribution cables and in the distribution transformer are quantified numerically for a typical UK distribution network running under typical domestic load profile for scenarios of installation of both BESS and renewable power sources. The effect of individual and integration of small scale DG units and ESS on energy losses is presented. The impact of using BESS to reduce variation in the power consumption on the network components, in particular distribution transformers, is thoroughly considered in this investigation, this is gauged through the extension of transformer life. The results show the superior benefits of distributed storage elements over bulk storage, despite its aggregated larger size. It is also shown that BESS can significantly reduce the loss of life of the distribution transformers. 


\section{Fundamentals}

The flow of electrical energy from generation source to end user (industrial, commercial or residential) via a transmission system, transformers and distribution cables, suffers from losses due to network components' impedances. The power losses are a function of the square of the load current.

\subsection{Impact of ESS on System Losses}

In general, the recorded losses in a power system network fall into three main categories; variable losses, referred to as copper losses, and the main concern of this research; these occur in transmission lines, transformers, and cables, and are dependent on the load current transmitted. Fixed losses occur mainly in transformer cores and do not vary with load current, these are normally ignored due to their low value compared to variable losses. Non-technical losses: Represent the electrical energy produced and consumed but not paid for due to meter errors or illegal abstraction. Variable losses, labeled as power losses, are high during the peak load period due to high current flow, as shown generally in Figure 1. It is clear from the graph that for the same change in load current (5 Amps) the losses are significantly higher during peak times ( 2 kWatt) than in off-peak periods ( 1 kWatt).

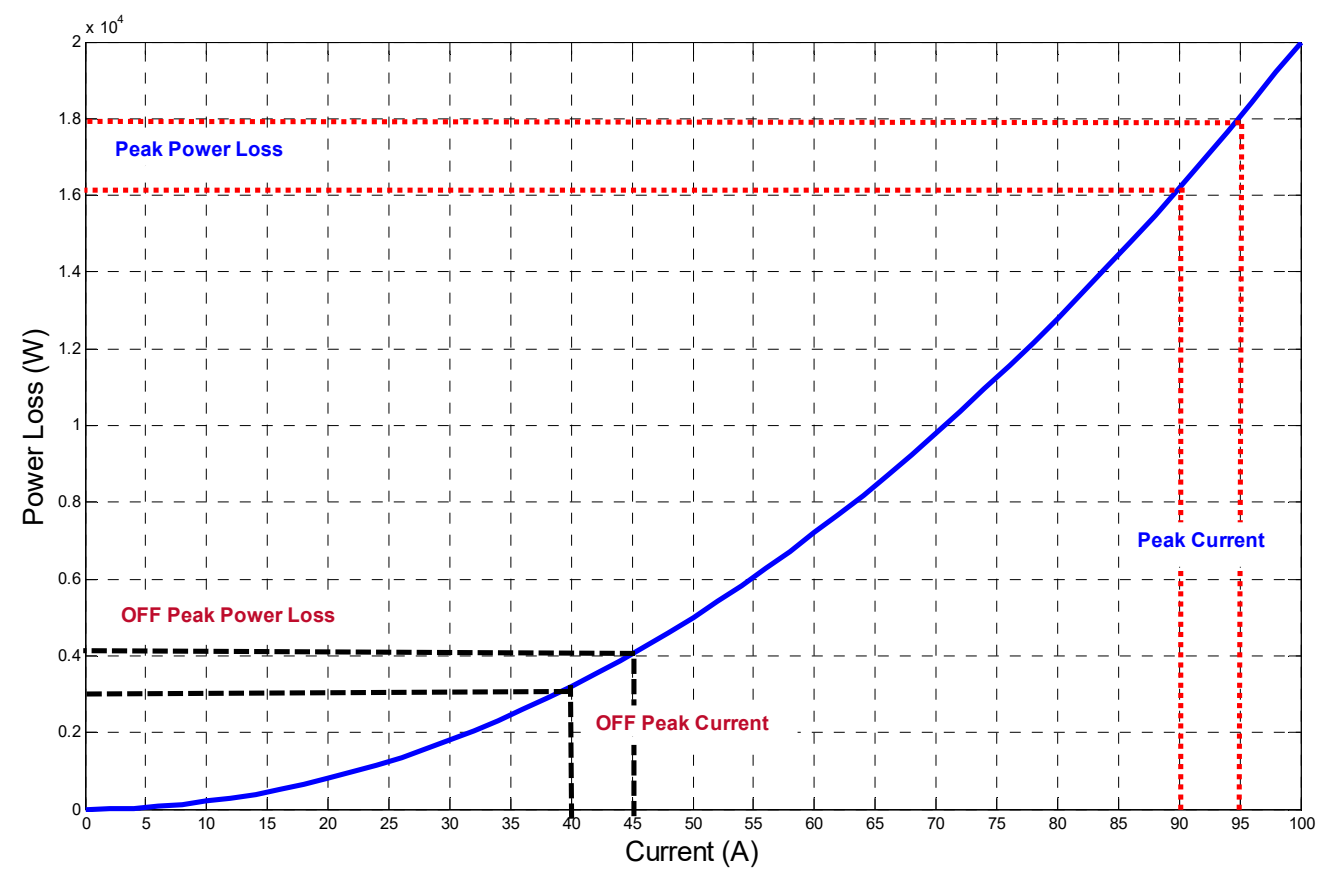

Figure 1. System losses (W) versus load current (A).

Using ESS to shift a fraction of the peak load current to the off-peak period is expected to impact on the system energy losses. It should, however, be noted that some of the savings made during peak times are offset by increased off-peak losses due to the current supplied from the ESS. In contrast, savings will result from the fact that the net resistance losses due to higher cable temperature at peak times will be decreased. These factors can outweigh the losses within the storage elements. The degree of savings through a reduction in energy losses will be affected by the location, rating, and efficiency of the ESS. Figure 2 shows the main components of losses in a generic model of a radial power system: $\mathrm{G}$ is the generating source. 


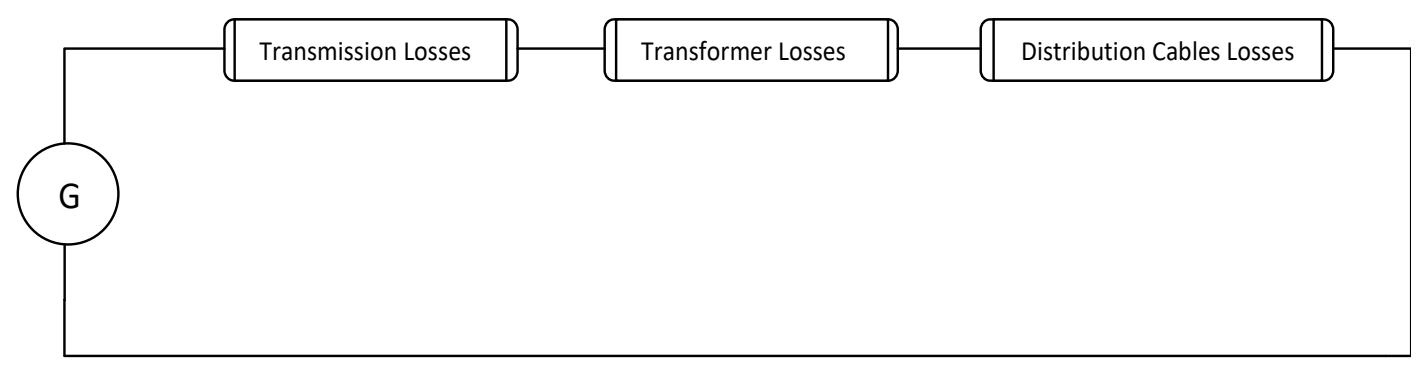

Figure 2. Losses in a generic radial power system.

Total losses in a network over a period of time (e.g., daily or annually):

$$
P_{L}=\sum R_{e q}(t) \times I_{e q}^{2}(t)
$$

where $P_{L}$ is the power loss, $R_{e q}=R_{\text {T.Line }}+R_{\text {Trans }}+R_{\text {Cables }}$ is the equivalent resistance of the grid elements; $R_{\text {T-Line }}$ is transmission line resistance, $R_{\text {Trans }}$ is transformer resistance and $R_{\text {Cables }}$ is the resistance of distribution cables. $I_{e q}$ is the equivalent current taking into consideration the voltage levels on both sides of a transformer.

To obtain the ideal situation of level load, the average load current $\left(I_{a v}\right)$ is determined based on the average power consumption, as indicated in Figure 3. In the proposed system, the average current is maintained at this level through charging and discharging of the BESS, as indicated in Figure 3. Although the network current downstream of the BESS will be load driven, i.e., variable profile, the current upstream will be kept consistent and level by the BESS operation cycle, resulting in potential savings and impact on the expected/remaining life of network components. This study investigates the potential energy savings from BESS installation in a DN as either bulk-storage or diversely distributed. The impact of BESS on the loss of life of the system components, particularly the DT will be addressed in detail. The investigation of the loss of life of the considered component will be considered under different scenarios for BESS installations.

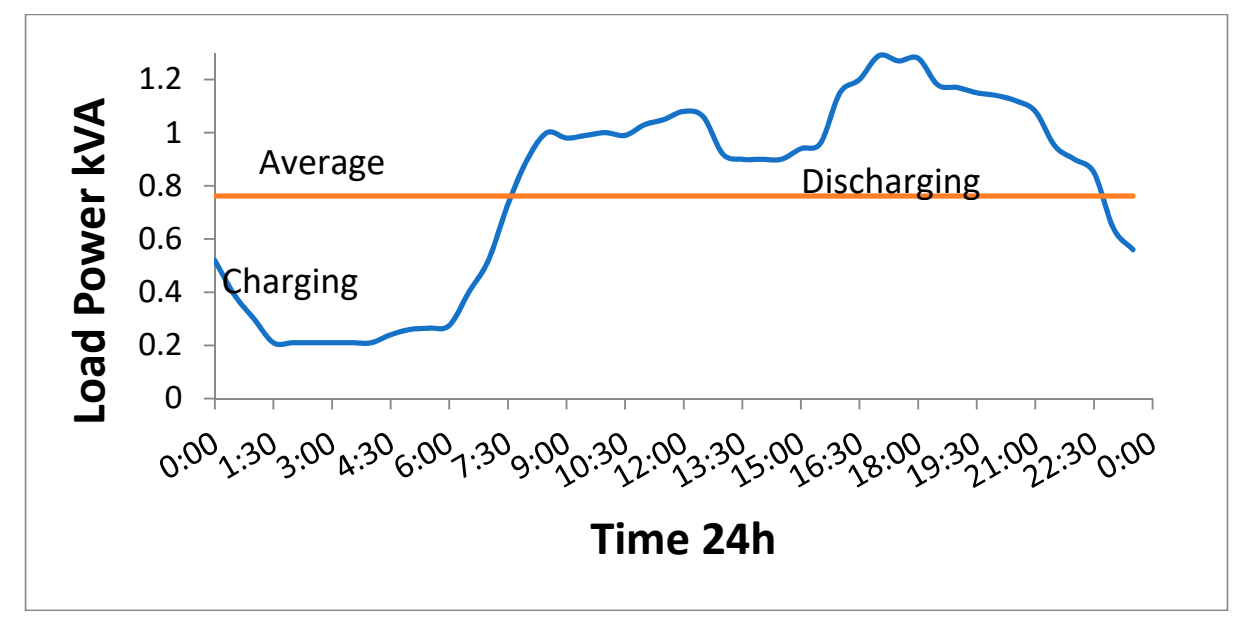

Figure 3. Generic load power.

Three situations of BESS installation within the DN are addressed; the corresponding power loss equation in each case is given as follows:

$>$ Bulk BESS installed at MV-side of the distribution transformer (DT),

$$
P_{L}=R_{T . \text { Line }} \times I_{a v}^{2}+R_{\text {Trans }} \times I_{\text {var }}^{2}+\sum_{\text {load }=1}^{n} R_{\text {Cables }} \times I_{\text {var }}^{2}
$$


$>$ Bulk BESS installed at LV-side of the DT,

$$
P_{L}=R_{\text {T. Line }} \times I_{a v}^{2}+R_{\text {Trans }} \times I_{a v}^{2}+\sum_{\text {load }=1}^{n} R_{\text {Cables }} \times I_{\text {var }}^{2}
$$

$>$ Uniformly distributed BESS at load buses,

$$
P_{L}=R_{T . \text { Line }} \times I_{\text {var }}^{2}+R_{\text {Trans }} \times I_{\text {var }}^{2}+\sum_{\text {load }=1}^{n} R_{\text {Cables }} \times I_{a v}^{2}
$$

where, $P_{L}$ is the power loss, $R$ values are as defined above, $I_{v a r}$ is the time dependent current taken by the variable loads and $I_{a v}$, is the average current in the segment, as driven by the BESS operating cycle.

\subsection{Impact of DG on System Losses}

A number of studies have been conducted to increase the value of wind power in the deregulated market, e.g., [24]. The integration of energy storage to wind generation systems in the frequency control market has shown the importance of merging the two technologies together [25,26]. In order to study the impact of an integrated system (wind and storage) on the distribution system operation, particularly the system losses, the power produced by the DG is transformed into its equivalent current that will be used to offset the load demand or to contribute directly to the stored energy in the ESS, battery bank for example. Two situations of DG installation were considered in this research; bulk penetration installed at the LV-side of the DT or uniformly distributed at the load buses. The power losses in these two cases are, respectively, given as follows:

$$
\begin{gathered}
P_{L}=R_{T . \text { Line }} \times I_{a v_{-} W T}^{2}+R_{\text {Trans }} \times I_{a v_{-} W T}^{2}+\sum_{\text {load }=1}^{n} R_{\text {Cables }} \times I_{\text {var }}^{2} \\
P_{L}=R_{\text {T. Line }} \times I_{\text {var_WT }}^{2}+R_{\text {Trans }} \times I_{\text {var_WT }}^{2}+\sum_{\text {load }=1}^{n} R_{\text {Cables }} \times I_{a v \_W T}^{2}
\end{gathered}
$$

where $P_{L}, R_{T-\text { Line }}, R_{\text {Trans }}$ and $R_{\text {Cables }}, I_{a v}$ and $I_{\text {var }}$ values are as defined previously, $I_{a v \_W T}$ and $I_{\text {var_WT }}$ are the time dependent and average currents from the wind turbines $I_{a v_{-} W T}=I_{a v}-\operatorname{average}\left(I_{W T}\right)$, and $I_{\text {var_WT }}=I_{\text {var }}-I_{W T}$.

In this study, $11 \mathrm{~kW}$ wind turbines are assumed to be suitable for installation at the LV side. The data employed in this study has been collected from an $11 \mathrm{~kW}$ rated wind turbine which is installed in a test site. The data are collected over one year, to include all-seasonal environmental impacts. As shown in Figure 4, the power-wind speed curve satisfies the standard formula of wind generation.

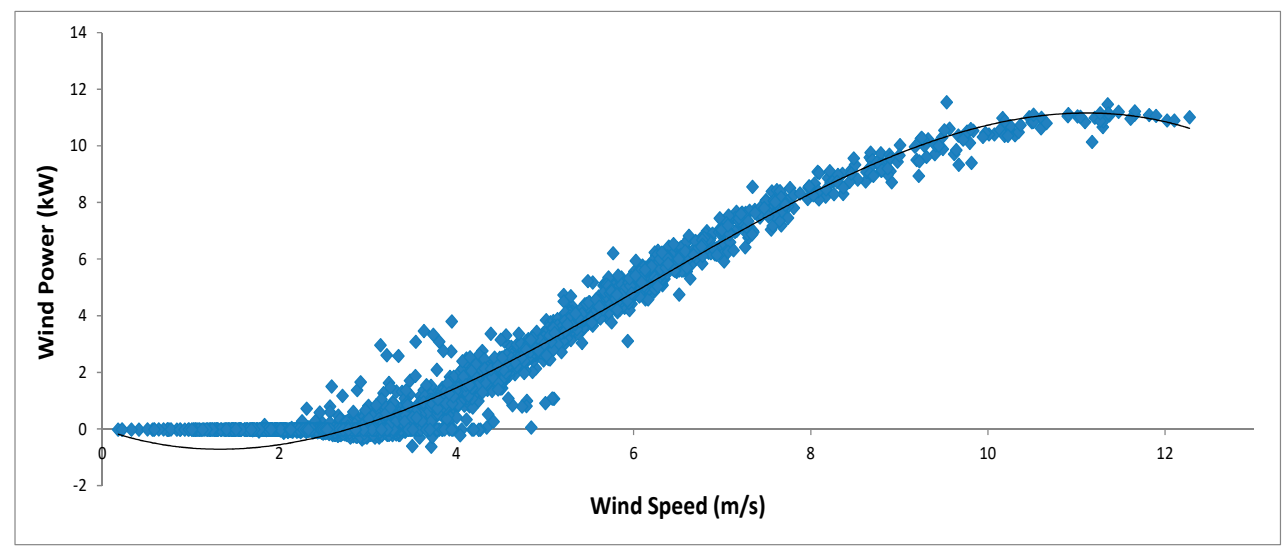

Figure 4. Wind power vs. wind speed for the $11 \mathrm{~kW} \mathrm{WT} \mathrm{used.}$ 
An example of an average daily variation in output power for this WT at the test site is presented in Figure 5. It is clear that the maximum wind energy production is around $60 \%$ of rated power for $25 \%$ of the day.

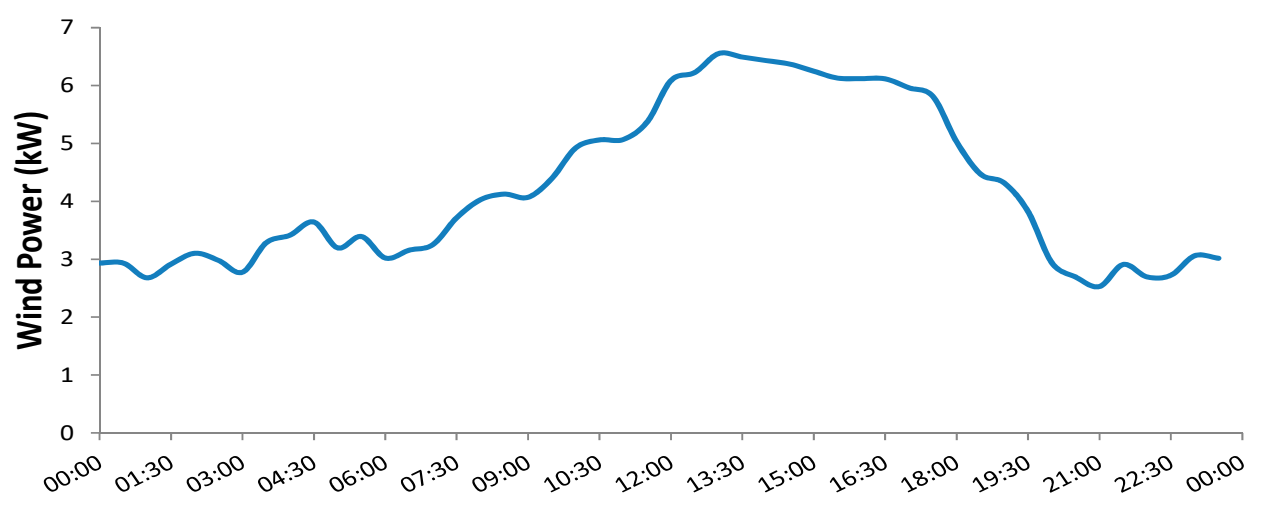

Time 24h

Figure 5. Daily average power of the $11 \mathrm{~kW}$ WT.

The annual distribution of wind speeds and the power production which resulted for this wind generator is shown in Figure 6, where the negative values at low wind speed are due to power absorbed from the grid to keep the wind induction generator running.

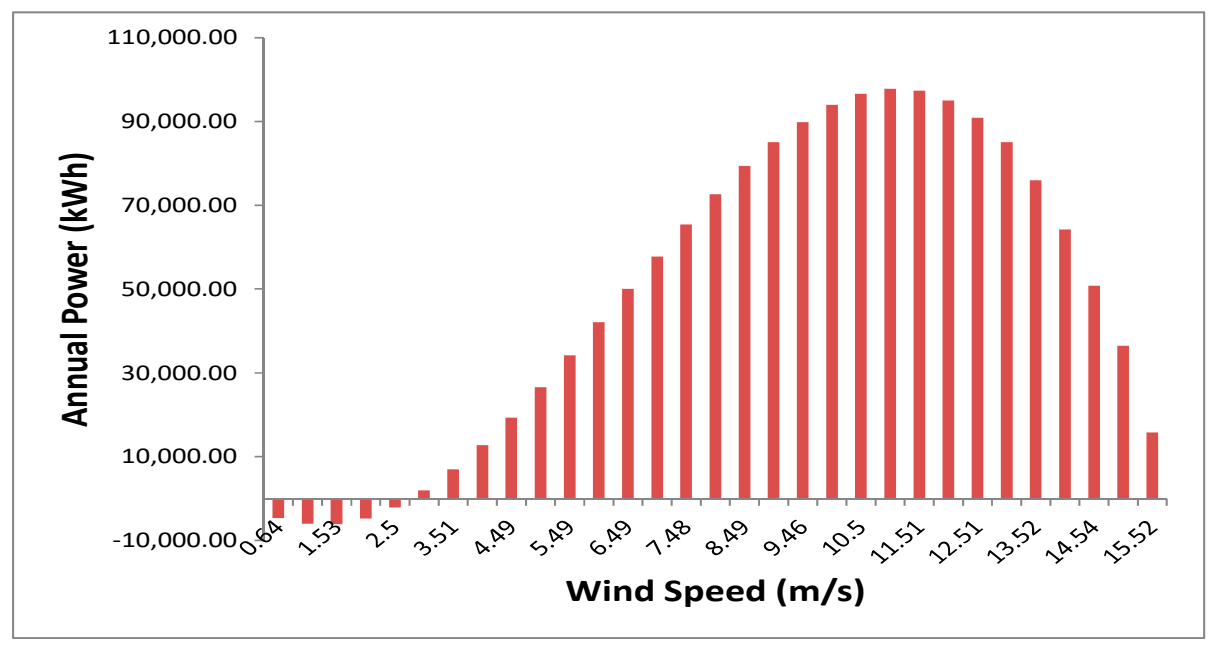

Figure 6. Annual wind power of the $11 \mathrm{~kW}-\mathrm{WT}$.

\section{UK Distribution Network}

\subsection{Typical Distribution Network}

A typical UK distribution network has been defined in [27] and is adopted in this work to investigate the research objectives. As shown in Figure 7, it consists of a $33 \mathrm{kV}, 500$ MVA grid point that is connected to a $33 / 11 \mathrm{kV}$ substation which supplies six $11 \mathrm{kV}$ feeders, each $11 \mathrm{kV}$ feeder supplies eight $11 \mathrm{kV} / 400 \mathrm{~V}(500 \mathrm{kVA})$ distribution transformers, each DT supplies 384 homes.

The detailed distribution of the 384 homes on the 400-V feeder is shown in Figure 8. The upper figures in this diagram are the cable length between adjacent busbars: the lower figures are the number of homes connected to a particular busbar. It is assumed that each busbar has four parallel branches of 96 homes each and equal cable length. The network parameters (cable lengths, resistances, and reactances) are provided in detail in Appendix A [28]. 


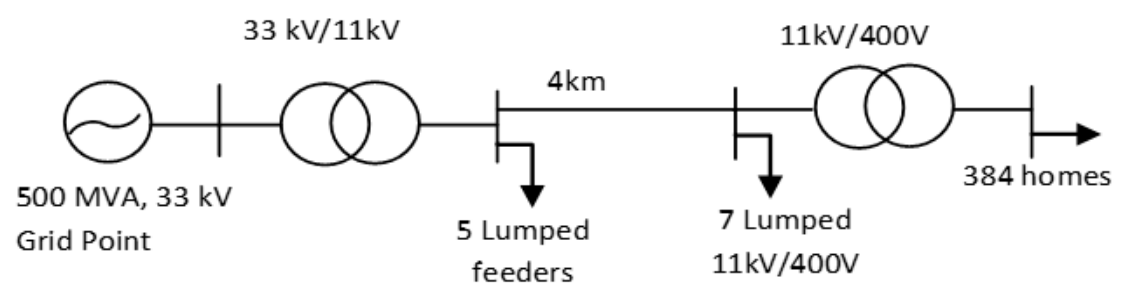

Figure 7. Typical UK distribution network [27].

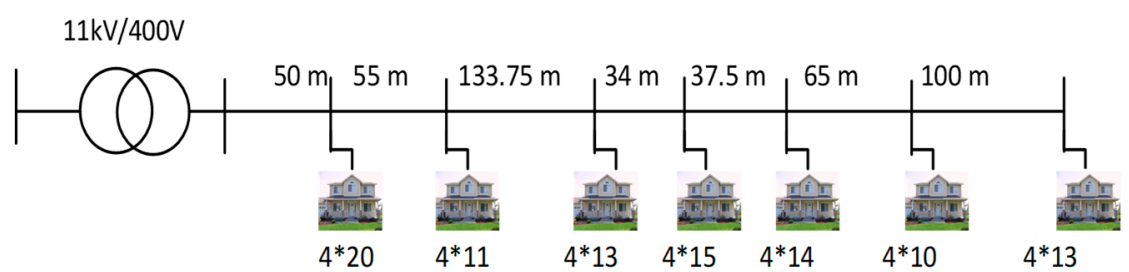

Figure 8. Detailed 400-V feeder.

\subsection{UK Load Profile and DT Losses}

The daily load profile of the UK distribution network is shown in Figure 9, based on after-diversitymaximumdemand (ADMD) referenced to 100 consumers [29]. Although the load profile is known to vary from winter to summer, for the purpose of simplicity an average annual load profile is adopted in this work.

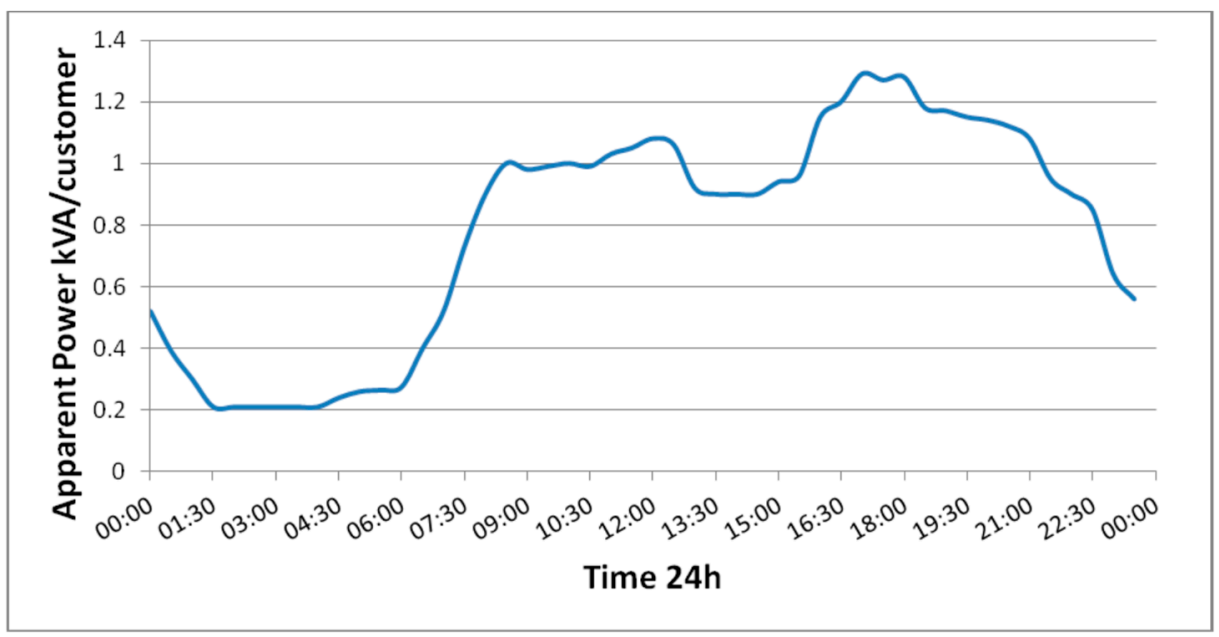

Figure 9. Annualised average daily load.

Transformer loading conditions are probably most influential as far as optimum selection of DT is concerned. Generally, for heavily loaded transformers, the focus should be on load losses while for lightly loaded, it should be on no-load losses. In Figure 10 Peak Load is shown as a solid line, the average load (Load Aver) is shown as a dotted line, transmission losses (Trans Loss) is a dash-dot line, and average transmission (Trans Aver) is shown as a dashed line. It is obvious from Figure 10 that, for the distribution transformer being studied, high levels of losses occur around $50 \%$ to $60 \%$ of peak load time. However, if the load curve is a flat line (equal load all the year with the help of demand-side techniques or ESS) both peak load and peak losses time will be constant. 


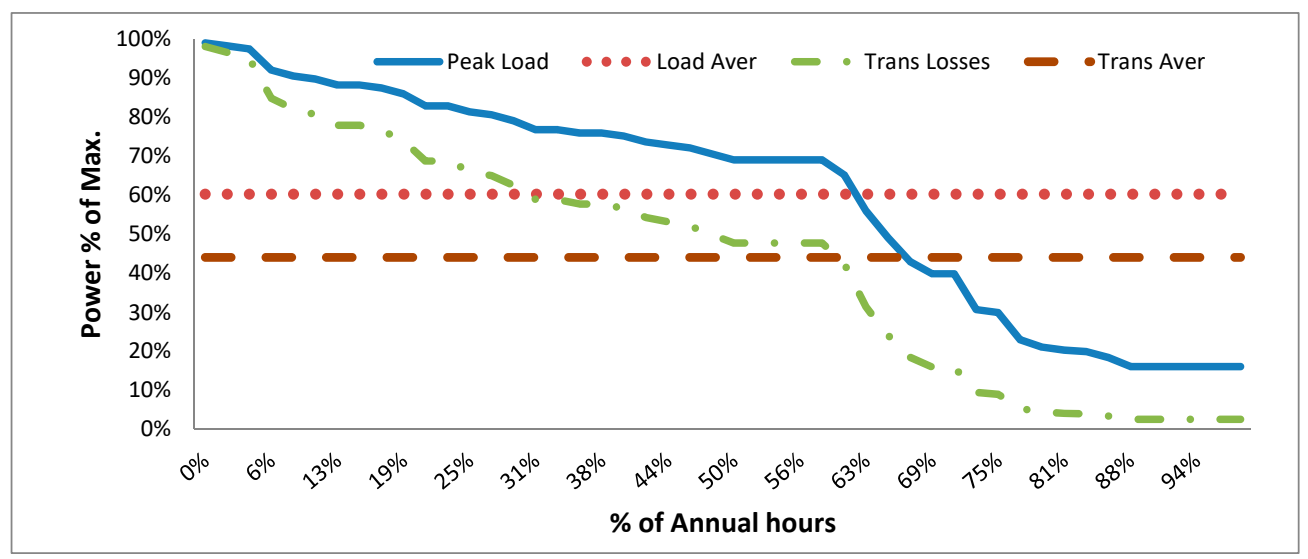

Figure 10. Relationship between DT peak load and peak loss time.

\section{Loss of Life of a Distribution Transformer}

The life of a transformer depends on the life of its solid insulation, which ages mainly due to the effect of temperature. The application of ESS will affect the load profile applied to the equipment and, as a consequence, will also alter the evolution of the temperature profile within the transformer insulation through time.

Simulations have been carried out to determine the effect on the life of a transformer of using BESS. The model proposed by IEEE Standard C57.92-1995 has been applied to calculate the temperature distribution in the transformer, and also to calculate the transformer loss of life under different operation scenarios.

\subsection{Calculation of Transformer Temperatures}

The thermal model of IEEE Standard C57.92-1995 provides equations to calculate the top oil temperature $\left(T_{t o}\right)$ and the hottest spot point temperature $\left(T_{h}\right)$. The hottest spot of the transformer tends to be in the upper part of the winding and its temperature will determine the aging rate of the equipment when it is subjected to certain loading conditions.

The top oil temperature $\left(\Delta T_{t o \_} u\right)$ rise over ambient temperature under steady state conditions and can be calculated for a load factor $\mathrm{k}$ as:

$$
\Delta T_{t o \_}=\Delta T_{t o \_} \times\left(\frac{k^{2} \times R+1}{R+1}\right)^{n}
$$

where $\Delta T_{\text {to } \_}$is the top oil temperature rise over ambient temperature at rated load, $R$ is the ratio of rated loss at rated load to no-load loss and $\mathrm{n}$ is a coefficient that depends on the cooling mode of the transformer.

The model considers that the top oil temperature in the transformer varies following a first-order law. Accordingly, the top oil temperature rise over ambient temperature at time, $t$, can be calculated as follows:

$$
\Delta T_{t o}(t)=\left(\Delta T_{t o-}-\Delta T_{t o \_}\right) \times\left(1-e^{\frac{-t}{\tau_{t o}}}\right)+\Delta T_{t o_{i}}
$$

where $\Delta T_{t o-}$ is the top oil rise over ambient at the beginning of the studied period $(t=0)$, and $\tau_{t o}$ is the time constant of the oil, which depends on the weight of different elements of the transformer.

The hottest spot temperature rise over top oil temperature $\left(\Delta T_{h}=T_{h}-T_{t o}\right)$ can be calculated according to Equation (9) below

$$
\Delta T_{h}(t)=\left(\Delta T_{h_{-} u}-\Delta T_{h_{-} i}\right) \times\left(1-e^{\frac{-t}{\tau_{w}}}\right)+\Delta T_{h_{-} i}
$$

where $\Delta T_{h_{-} i}$ is the hottest spot rise over top oil temperature at the beginning of the studied period, $\tau_{w}$ is the time constant of the winding, and $\Delta T_{h_{-} u}$ is the hottest spot rise over top oil temperature in the steady-state for the considered load which can be calculated as: 


$$
\Delta T_{h \_u}=\Delta T_{h \_r} \times(k)^{2 \cdot m}
$$

where $\Delta T_{h_{-} r}$ is the hottest spot rise over top oil temperature for rated load, and $\mathrm{m}$ is a coefficient that depends on the transformer cooling mode.

\subsection{Loss of Life Calculation}

The IEEE standard considers that if the hottest spot temperature exceeds $95^{\circ} \mathrm{C}$, the aging process of the transformer will be accelerated in a factor $F_{A A}$; which can be calculated as follows:

$$
F_{A A}=\left(\frac{15000}{383}-\frac{15000}{T_{h}+273}\right)
$$

Finally, to calculate the equivalent loss of life $\left(F_{E Q A}\right)$, in hours or minutes, that is consumed in a period of time $t$ composed of $n$ periods $t_{n}$, Equation (11) is proposed as Equation (12). The loss of life is expressed in minutes or hours depending on the unit considered for the time-periods $t_{n}$.

$$
F_{E Q A}=\frac{\sum_{n=1}^{N} F_{A A n} \Delta t_{n}}{\sum_{n=1}^{N} \Delta t_{n}}
$$

\section{Case Studies}

The single line diagrams of the system under study were shown in Figures 7 and 8. As previously indicated, for simplicity, only variable losses are considered. The impact of BESS and DG installation on the system losses is investigated for various locations, i.e., centralized and distributed. Three locations for the BESS are considered: (i) bulk installation at $11 \mathrm{kV}$ (MV) side of the DT, (ii) bulk installation at the $400 \mathrm{~V}$ (LV) side of the DT and (iii) distributed installation at $400 \mathrm{~V}$ busbars, of course the converter size at each location is proportional to the level of BESS installation. Different penetration levels of DG's are considered at two locations (i) bulk installation at the LV side of the DT and (ii) distributed installation at the $400 \mathrm{~V}$ busbars. Four scenarios were investigated to determine the impact of BESS and DG's on-grid losses and cost savings opportunities.

\subsection{Scenario 1: Bulk BESS is Installed at the MV/LV Side of the DT}

The annual load demand of the system under consideration is 10,248 MWh. Table 1 shows the annual MV cable, DT and distributed (D) cable losses with no BESS and with BESS installed at either side of the DT. It is clear that with BESS installed at the LV side of the DT, there is a reduction in loss equivalent to $43.3 \mathrm{MWh}$ annually and, as a result, significant financial saving opportunities. Also, the losses are reduced by $0.423 \%$ with respect to the total annual load demand energy.

Table 1. Grid losses with battery energy storage system (BESS) only.

\begin{tabular}{cccccc}
\hline & & D.T. Loss & T.L. Loss & D. Cables Loss & Aggregate Loss \\
\hline \multirow{2}{*}{ With no BESS } & MWh & 123.237 & 122.697 & 2437.02 & 2682.954 \\
& $\%$ & 1.203 & 1.197 & 23.78 & 26.18 \\
\hline \multirow{2}{*}{ BESS @ MV } & MWh & 123.237 & 101.098 & 2437.02 & 2661.355 \\
& $\%$ & 1.203 & 0.986 & 23.78 & 25.969 \\
\hline \multirow{2}{*}{ BESS @ LV } & MWh & 101.542 & 101.098 & 2437.02 & 2639.66 \\
& $\%$ & 0.991 & 0.986 & 23.78 & 25.757 \\
\hline \multicolumn{7}{c}{ BESS (Battery capacity) AH @ $400 \mathrm{~V}$} \\
\hline
\end{tabular}

\subsection{Scenario 2: BESS is Installed at Distribution Buses}

In this scenario, the energy storage system is locally installed at each busbar that connects to a group of houses, as depicted in Figure 8. The main purpose is to minimize variation in consumed 
power at each busbar locally through the installation of the BESS subsystems. Table 2 shows that, compared to the case when bulk BESS is installed at the LV-side of the DT (Scenario 1), although there is no significant change in the power losses for both TL cable and DT, there is $4.2 \%$ savings in the D-cables. On the other side, and as a demerit for this scenario, the storage capacity has to be increased by $78.6 \%$. Economically, the benefit of the power loss reduction in the D-cables is offset by the cost associated with high capacity of BESS at busbar level.

Table 2. Grid losses with distributed BESS.

\begin{tabular}{cccccc}
\hline & & D.T. Loss & T.L. Loss & D. Cables Loss & Aggregate Loss \\
\hline \multirow{2}{*}{ BESS @ LV } & MWh & 101.542 & 101.098 & 2437.02 & 2639.66 \\
& $\%$ & 0.991 & 0.986 & 23.78 & 25.757 \\
\hline \multirow{2}{*}{ D-BESS } & MWh & 101.542 & 101.098 & 2008.01 & 2210.65 \\
& $\%$ & 0.99082 & 0.98648 & 19.594 & 21.5713 \\
\hline \multicolumn{5}{c}{ BESS (Battery capacity) AH @400 V for D-BESS } & $\mathbf{2 5 , 8 5 1 . 9}$ \\
\hline
\end{tabular}

\subsection{Scenario 3: Integration of $D G^{\prime}$ 's and BESS}

It is anticipated that the installation of DG in the distribution network will contribute to energy savings and reduction of power demand from macro-generators. The impact of the location of installed WT's on the BESS rating and grid losses are considered in this scenario. WT's capable of producing $10 \%$ of the distribution transformer rating is installed at the DT LV-side or as distributed small-scale generation (DWT) at the busbars. This is studied for situations where BESS has been installed on either side of the DT. Table 3 shows, for comparison with the previous scenarios, the energy-saving opportunities. It is clear that the aggregate losses are reduced when bulk storage is installed at the LV-side of the DT and WT's are installed at homes busbars, as shown in Figure 11. Although the storage capacity required is slightly increased over scenario 1, it is lower than the case when distribution BESS is considered as discussed in scenario 2 . The penetration of WT's (10\%) has resulted in reduction of the power losses in each network component with aggregate value of $3.24 \%$, this is clear through comparison of data from Table 1 (BESS@LV) and Table 3 (DWT, BESS@LV).

Table 3. Grid losses with WT's and BESS.

\begin{tabular}{cccccc}
\hline & D.T. Loss & \multicolumn{2}{c}{ T.L. Loss } & D. Cables Loss & Aggregate Loss \\
\hline \multirow{2}{*}{ WT @LV, BESS@MV } & MWh & 107.931 & 87.066 & 2437.02 & 2632.017 \\
& $\%$ & 1.053 & 0.84957 & 23.78 & 25.683 \\
\hline \multirow{2}{*}{ WT @LV, BESS@LV } & MWh & 87.449 & 87.066 & 2437.02 & 2611.535 \\
& $\%$ & 0.8533 & 0.84957 & 23.78 & 25.483 \\
\hline \multirow{2}{*}{ DWT, BESS@LV } & MWh & 87.449 & 87.066 & 2133.55 & 2308.065 \\
& $\%$ & 0.8533 & 0.84957 & 20.818 & 22.521 \\
\hline \multirow{3}{*}{ BESS (Battery capacity) AH @400 V } & \multicolumn{3}{c}{ WT @LV, BESS@MV } & $\mathbf{1 3 , 9 9 4 . 3}$ \\
& & \multicolumn{5}{c}{ DWT, BESS@LV } & $\mathbf{1 3 , 9 9 4 . 3}$ \\
\hline
\end{tabular}

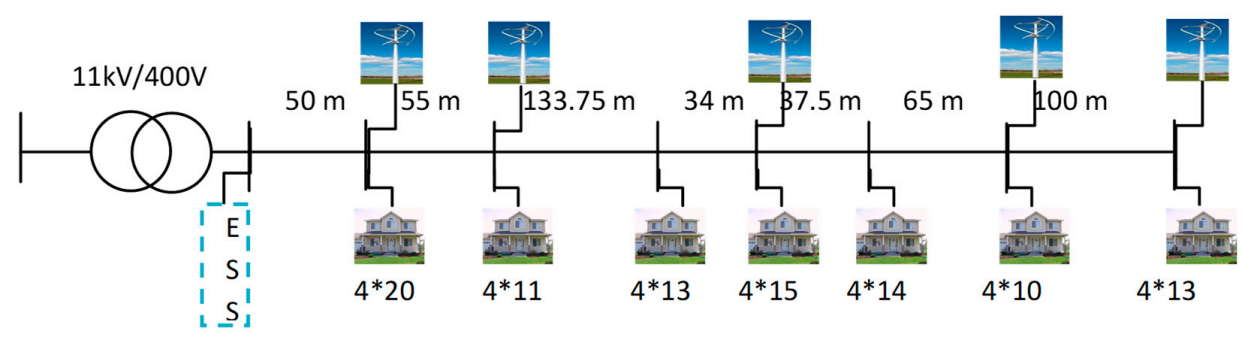

Figure 11. Detailed 400-V feeder with BESS and distributed WT's. 


\subsection{Scenario 4: High Penetration of DG's and BESS}

In this scenario the impact of distributing both WT and BESS at busbars is addressed, different levels of DG's penetration are also considered. As demonstrated through a comparison of data in Table 2 (D-BESS) and Table 3 (WT, BESS@LV), the installation of small scale D-BESS at each busbar significantly increases the storage capacity required to maintain the power consumption at its average, regardless of the level of WT installation. Also, by comparing data in Table 3 (DWT and BESS@LV) and Table 4 (DWT and D-BESS), with the same 10\% installed level of WT, the required D-BESS capacity is increased by $22.4 \%$. However, the installation of small scale WT at load busbars has resulted in a reduction of the losses in each component individually and overall. This is clear from comparing the second row of Table 2 and first row on Table 4, where $2.44 \%$ reduction in power losses is shown. Consequently, further increasing the level of WT penetration reduces the losses and required storage capacity as shown in Table 4.

Table 4. Grid losses with high penetration of WT and BESS.

\begin{tabular}{cccccc}
\hline & & D.T. Loss & T.L. Loss & D. Cables Loss & Aggregate Loss \\
\hline 10\% DWT and D-BESS & \% of total & 0.87 & 0.8662 & 17.397 & 19.1332 \\
20\% DWT and D-BESS & load & 0.7428 & 0.7396 & 14.883 & 16.3654 \\
$30 \%$ DWT and D-BESS & & 0.6258 & 0.6231 & 12.579 & 13.8279 \\
\hline \multicolumn{3}{c}{ BESS (Battery capacity) AH @400 V } & & $10 \%$ DWT and D-BESS (AH) & $\mathbf{1 7 , 7 1 7 . 5 1}$ \\
& & & 20\% DWT and D-BESS (AH) & $\mathbf{1 6 , 8 5 3 . 9 5}$ \\
& & & $30 \%$ DWT and D-BESS (AH) & $\mathbf{1 5 , 9 9 0 . 3 9}$ \\
\hline
\end{tabular}

\subsection{Scenario 5: DT Loss of Life Incorporating BESS}

The model proposed in IEEE Standard C57.92-1995 [30], has been applied to calculate the temperatures in a distribution transformer subjected to the load factor and ambient temperature profile given in Figure 12.

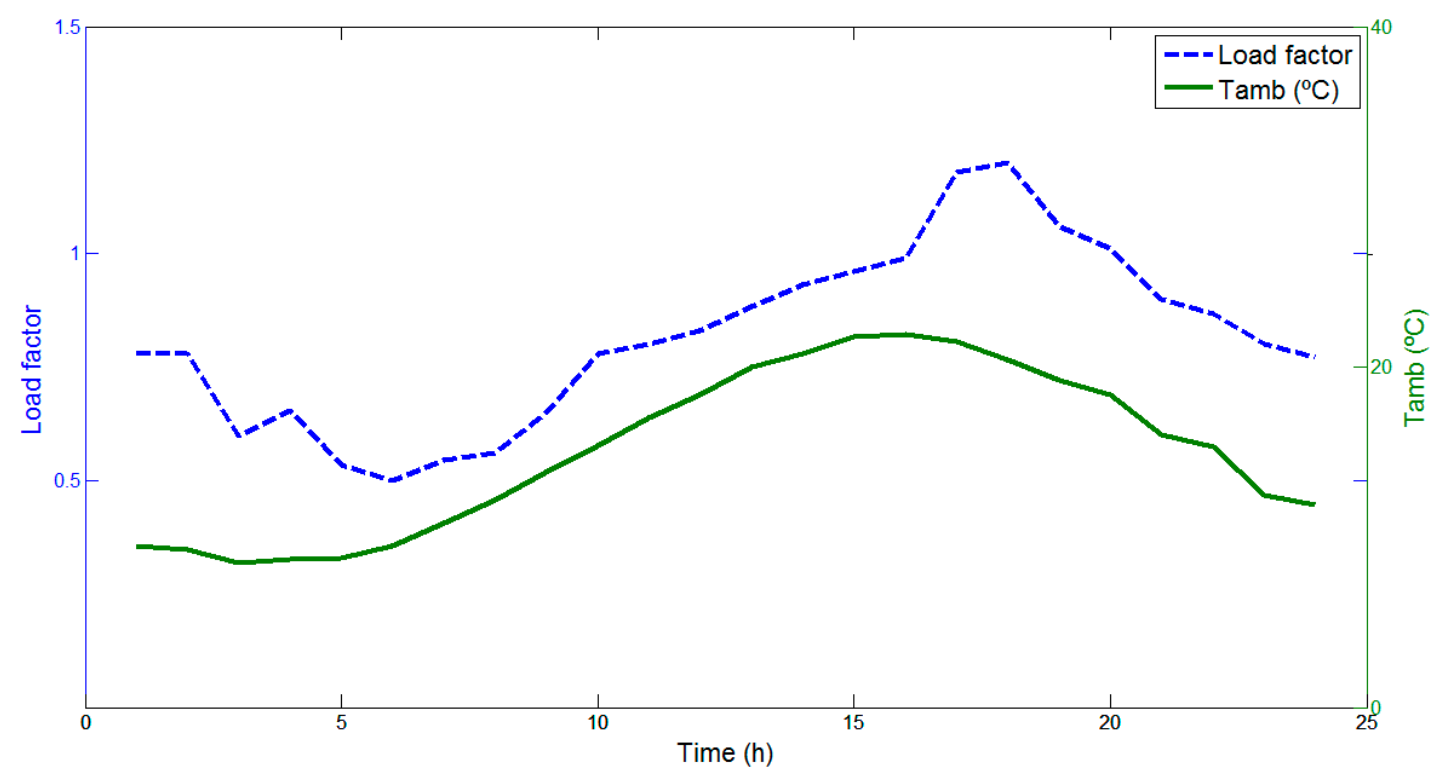

Figure 12. Variable load factor and ambient temperature considered in the study.

The distribution transformer parameters used for this study were obtained from the IEC Standard 354.1991 [31], the time constants considered, Table 5, were taken from [30,32]. 
Table 5. Parameters of the distribution transformer.

\begin{tabular}{ccc}
\hline Parameter & Value & Units \\
\hline$R$ & 5 & - \\
$\Delta T_{t o_{-} r}$ & 55 & ${ }^{\circ} \mathrm{C}$ \\
$\Delta T_{h_{-} r}$ & 23 & ${ }^{\circ} \mathrm{C}$ \\
$\mathrm{N}$ & 0.8 & - \\
$\mathrm{M}$ & 0.8 & - \\
$\tau_{t o}$ & 210 & Min \\
$\tau_{w}$ & 10 & Min \\
\hline
\end{tabular}

The temperatures for the transformer under study were then calculated with and without the BESS connected at the LV side of the transformer. With BESS, a constant load factor of 0.8152 was applied to the transformer, equal to the average value of the daily load.

The evolution of $T_{t o}$ and $T_{h}$ are shown in Figures 13 and 14 for both cases. As can be seen for the case of connecting an BESS at the secondary side of the transformer, Figure 13, the evolution of the temperatures is very smooth, and the maximum $T_{h}$ attained is below $85^{\circ} \mathrm{C}$ even during the peak ambient temperature. For the case of applying the daily load displayed in Figure 12, the temperature profile, despite its minimum being $45^{\circ} \mathrm{C}$, presents a peak of $T_{h}$ that exceeds $100{ }^{\circ} \mathrm{C}$, Figure 14 : This elevated temperature lasts for over four hours.

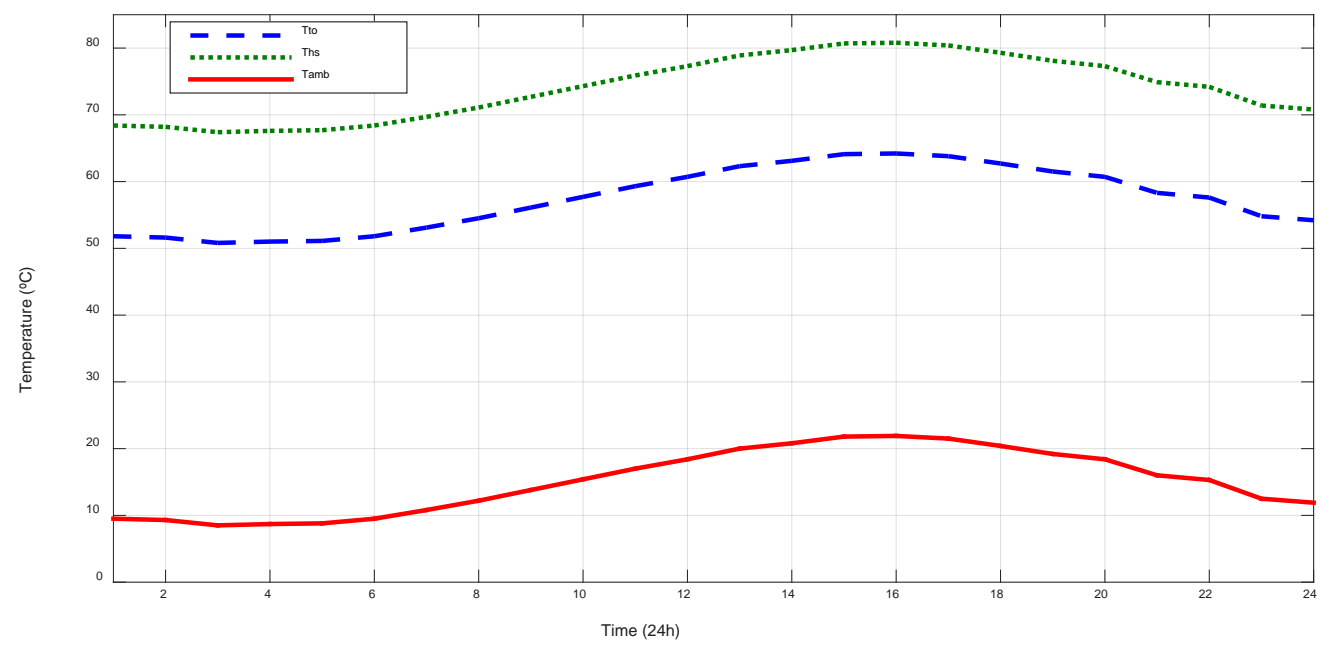

Figure 13. Transformer temperature variations with BESS.

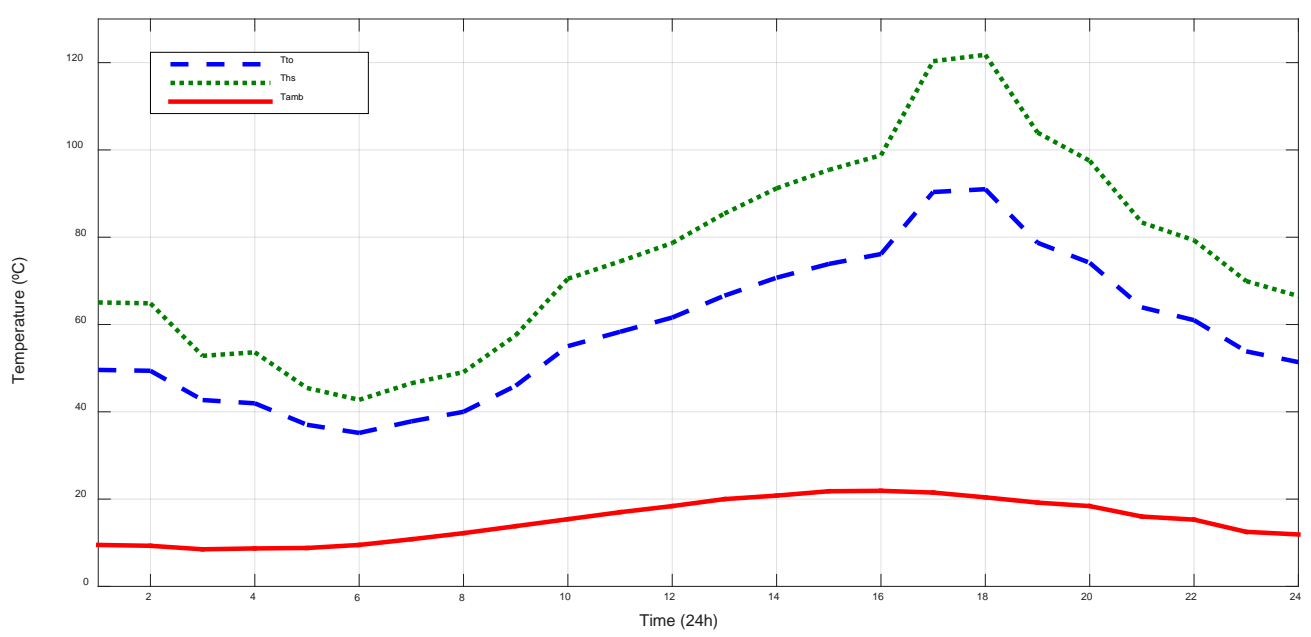

Figure 14. Transformer temperature variations without BESS. 
The aging acceleration factor has been calculated according to Equation (11), the results for both cases, with and without BESS, are shown in Figures 15 and 16, respectively. Note the change in scale of the $\mathrm{F}_{\mathrm{AA}}$ and the temperature axis in both Figures. As can be seen, $\mathrm{F}_{\mathrm{AA}}$ is almost nil when the temperatures are below $90{ }^{\circ} \mathrm{C}$, as happens if the BESS is connected at the secondary side of the transformer.

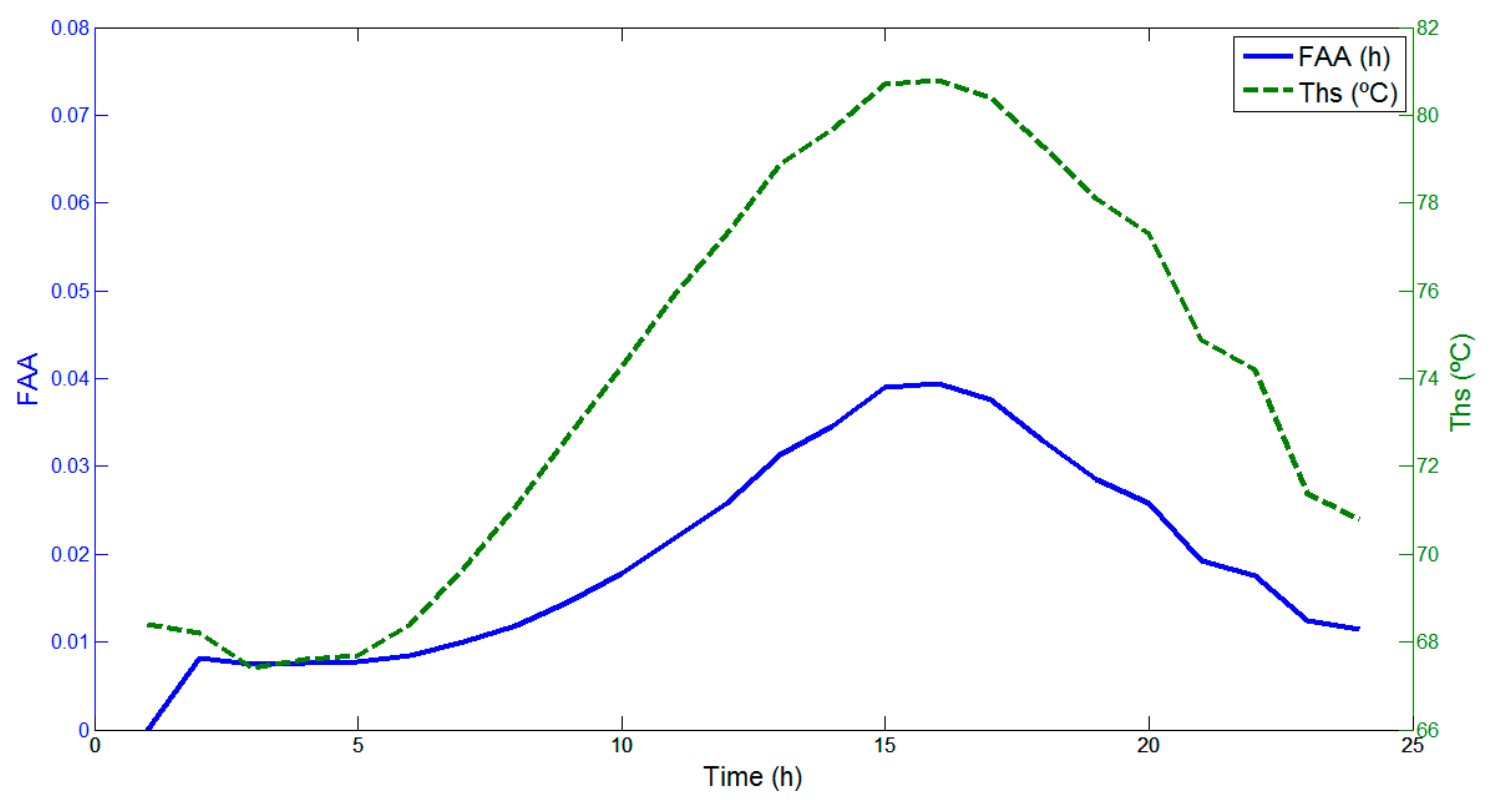

Figure 15. Transformer $F_{A A}$ and $T_{h s}$ with BESS.

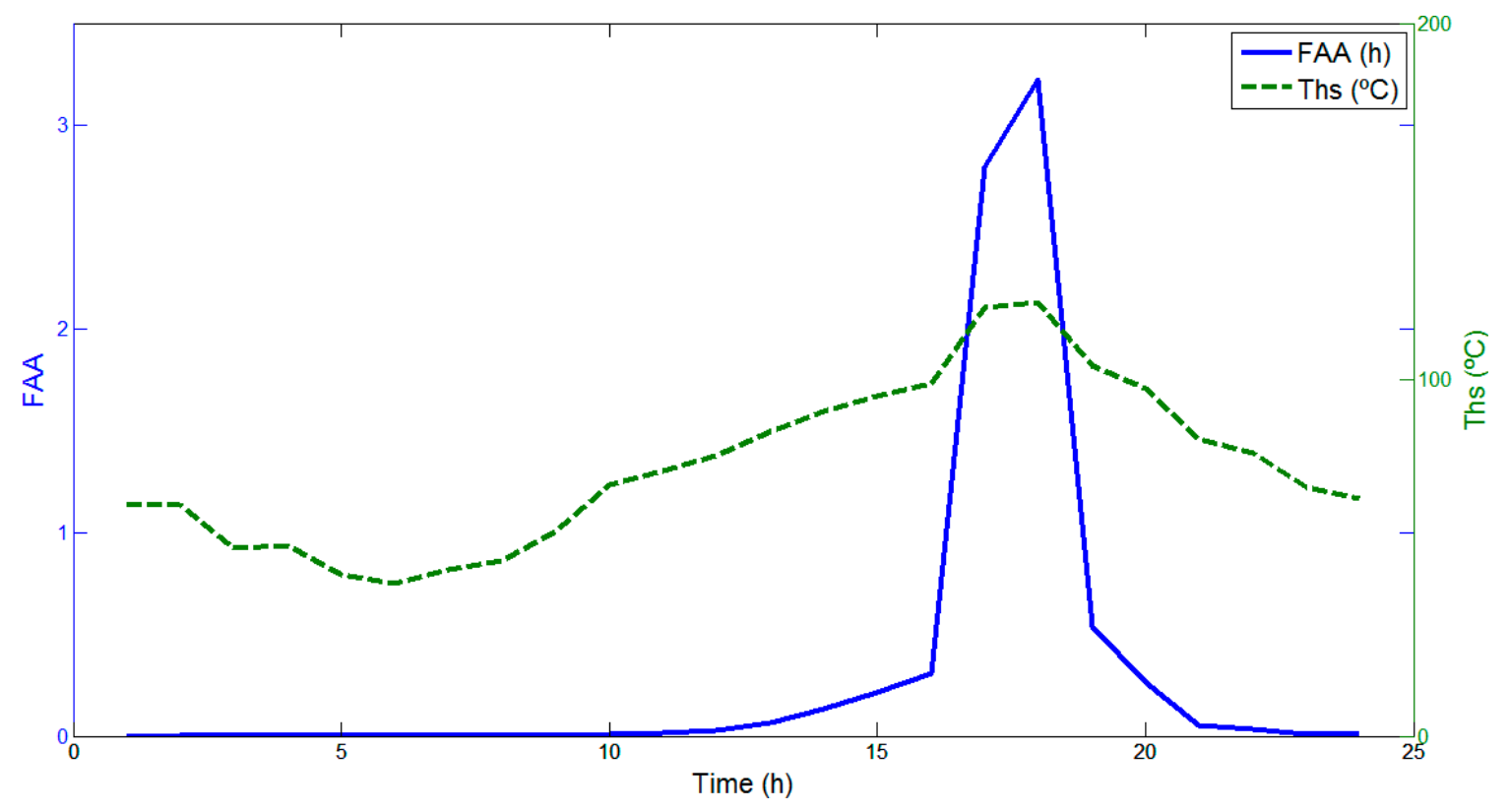

Figure 16. Transformer $F_{A A}$ and $T_{h s}$ without BESS.

Finally, the total loss of life in hours accumulated during the studied period has been calculated according to Equation (12). As can be seen, in Figure 17, the loss of life for the case of connecting the BESS is much lower than the case of the variable load profile. The loss of life calculated in both cases for the $24 \mathrm{~h}$ period was $0.47 \mathrm{~h}$ and $7.72 \mathrm{~h}$ respectively. 


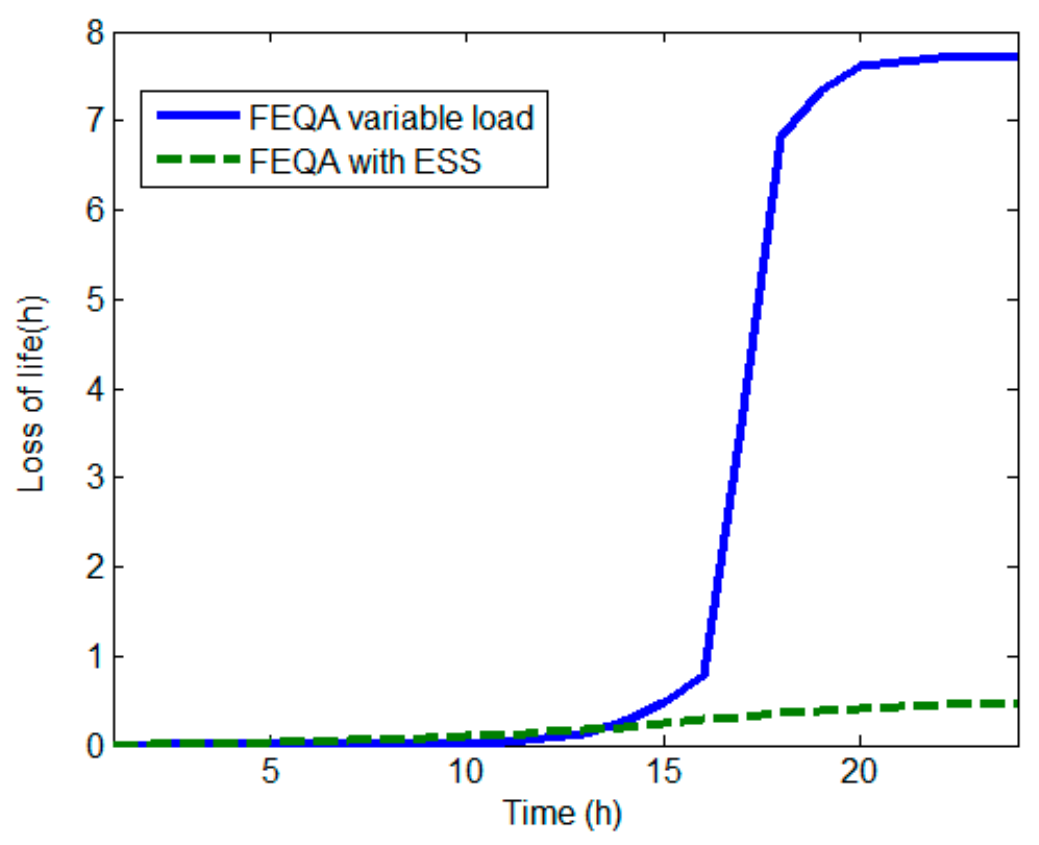

Figure 17. $\mathrm{F}_{\mathrm{EQA}}$ calculated for $24 \mathrm{~h}$ period with and without BESS.

\section{Discussion}

With the growth of global electrical energy demand and limited energy resources available, it is vital to improve the performance of the current energy infrastructure. Electrical energy is the main type of energy used in the dwells and, therefore, has a significant on climate change and greenhouse gas (GHG) emissions based on the method used to be generated. Using the current grid to its maximum capacity is a necessity for future sustainable development. Reduction in the grid losses is considered an essential means to increase grid efficiency and to extend the component's life, providing more cost-effective delivery of power to consumers. Installation of DG's, such as WT's, is expected to reduce the GHG emissions and to provide local energy generation for local load demand. Integration of energy storage systems and renewable energy sources are considered an optimal combination for minimizing the grid losses, while also leading to the possibility of extending the lifetime of the grid components.

This study investigated the integration of BESS and WT's at various locations in the distribution network. It is very obvious and expected as well that the installation of renewable sources (WTs in this case) is significantly reducing the power losses in the three studied components (line, cables, and transformer), as can be seen from Figure 18. In that figure, the minimum losses are recorded when both the renewable sources and battery energy storage are distributed at each load busbar. However, this has not led to the installation of minimum battery capacity. In comparing Figure 19 to the same cases in Figure 18, it is clear that the total rating of the battery capacity is obtained when the storage component is located either side of the distribution transformer as bulk storage. As shown in Figure 19, the minimum BESS required capacity occurs with distributed DG's sources and bulk storage BESS installed next to the LV side of the DT.

Following Figure 10, the peak load and transformer losses are given in Figure 20, as a result of the installation of $W^{\prime}$ 's, the peak load is reduced by $7 \%$ and the peak transformer losses is reduced by $11 \%$. However, with the aid of distributed BESS and WT's the peak losses are reduced significantly, to about $50 \%$ of its original value and improvement was shown through the year. 


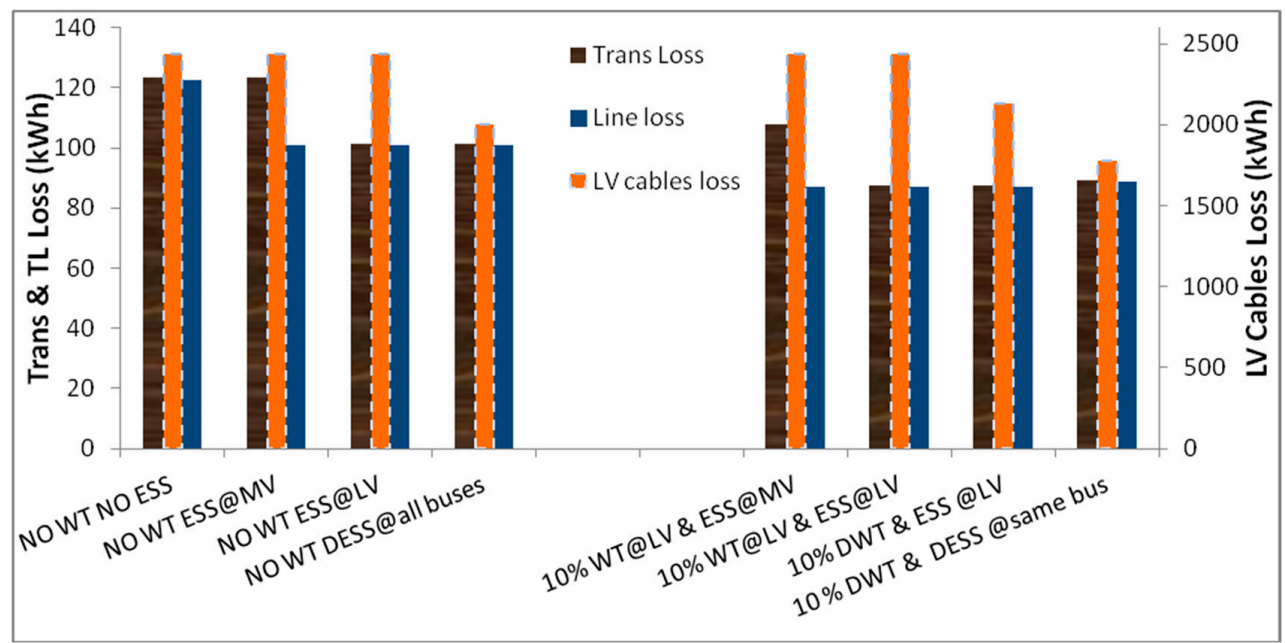

Figure 18. Summary of grid component losses.

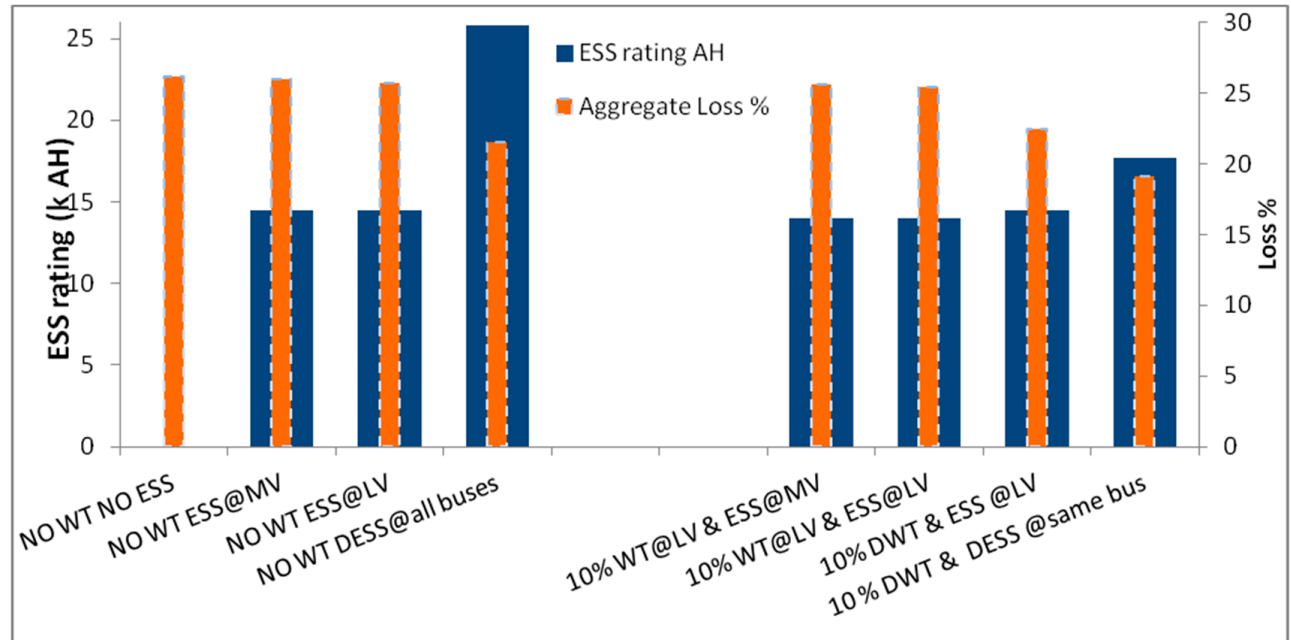

Figure 19. Summary of BESS rating and grid losses.

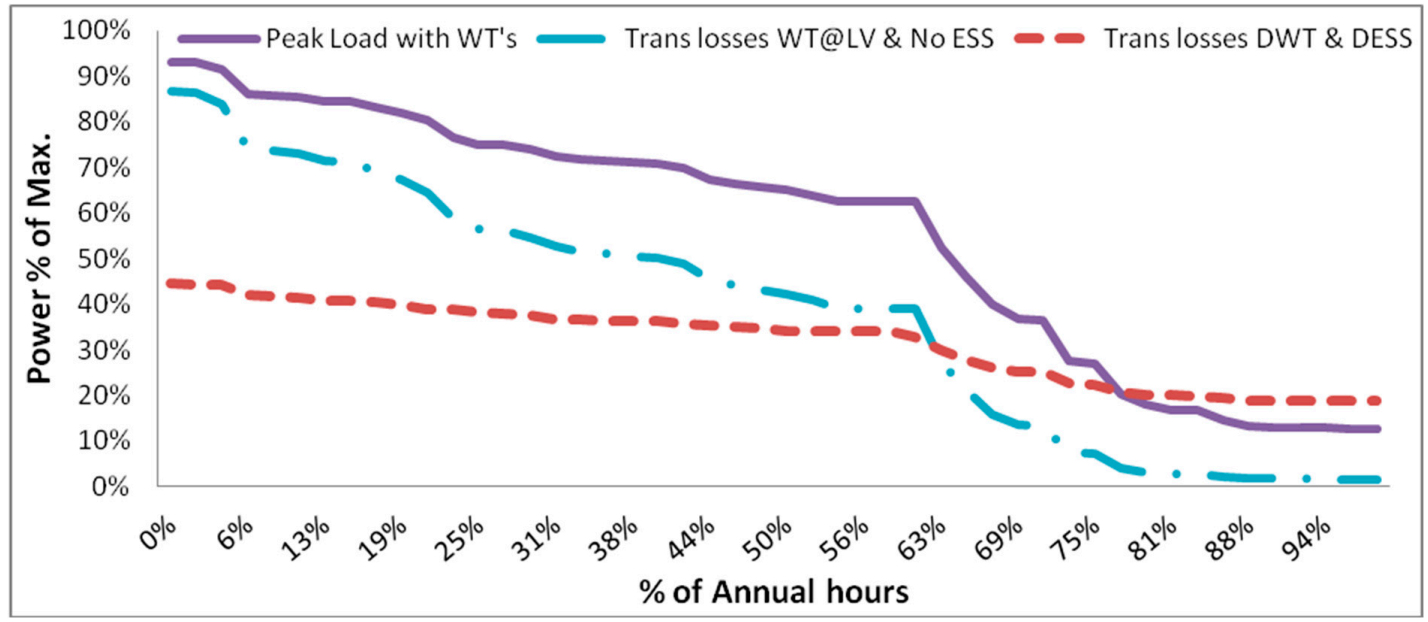

Figure 20. Peak load and transformer losses with BESS and WT's.

Installing bulk BESS and WT's at the LV-side of the DT has flattened the current (power loss) profile in the transformer and upstream components i.e., transmission cables. The averaged transformer power loss is $31.32 \%$ compared to $44.13 \%$ in the case where no BESS or WT's are installed. This leveled power loss rises to $36.36 \%$ if only distributed BESS is used, i.e., no WT's installation. However, there is 
no significant change (31.93\%) for the case when BESS and WT's are both distributed over the low voltage busbars. It was very obvious from simulation that in scenarios where BESS is connected the DT loss of life is much lower than the case of variable load profile. The loss of life calculated in both cases for the $24 \mathrm{~h}$ period was $7.72 \mathrm{~h}$ and $0.47 \mathrm{~h}$.

\section{Economic Evaluation of the Integrated System}

In future utility-scale operations, energy storage is expected to be the default approach for solving standard peak capacity challenges, rather than a traditional generator. BESS and DG have the ability to be modularized and placed in areas of the grid that require the most attention whereas traditional sources of generation, and the transmission and distribution system, are either impossible or too expensive to install. Placing the right storage technology at a key location can improve shortage of the supply conditions, relieve congestion, defer transmission, distribution or substation upgrades, or delay new capacity installation.

\subsection{Economic Evaluation of BESS}

Different types of Mega scale battery-based energy storage are currently installed worldwide. For example, lithium-ion (Li) and sodium-sulphur (NaS)-based battery technology with charging/ discharging efficiency (90-95\%), high energy/power density and up to 15-20 years (5000-10,000 cycles) of life have been installed at various sites across the globe for many years now. In Japan (34 MW of $\mathrm{NaS}$ and $30 \mathrm{MW}$ Li stored power is used for stabilising $51 \mathrm{MW}$ wind power [33]), in China (1 MW of $\mathrm{NaS}$ in Meisei University Campus, [34]), in Italy (35 MW of NaS commissioned in 2015 [35]), in USA (24 MW of NaS out of $545 \mathrm{MW}$ battery-based installed up to June 2016). India is aggressively pursuing energy storage as a secure power resource for over 300,000 telecom towers, $\$ 40 \mathrm{M} \mathrm{Li}$-ion battery energy storage systems is contracted to meet that need. South Korea has $54 \mathrm{MW}$ of Li batteries and UK is planning for $6 \mathrm{MW}$ battery storage.

Total capital cost (TCC) and life cycle cost (LCC) are the two main factors to evaluate and compare for different BESS systems. TCC includes purchase, installation, costs of power conversion systems and the balance of the equipment. LCC accommodates all expenses related to fixed/variable operation and maintenance, replacement, disposal and recycling in addition to TCC [36,37]. According to many researchers, there is lack of adequate information regarding the economy of utility-scale BESS, as many BESS costs are site-specific technologies, Table 6 presents the average cost analysis of Li and NaS battery energy storage collected from literature [38-40] for the capital cost including the power electronic ancillaries, the storage facilities, and the operation and maintenance. In addition, the BESS total cost for different scenarios addressed in Figure 19 is also presented reflecting a 15-years operational life cycle with consideration of $3.5 \%$ depreciation rate, as will explained below.

Table 6. Estimated BESS-battery cost.

\begin{tabular}{ccc}
\hline Cost Item & NaS & Li \\
\hline Power conversion system, grid connection and foundation $\$ / \mathrm{kW}$ & 384 & 486 \\
Storage section $\$ / \mathrm{kWh}$ & 300 & 275 \\
Fixed O\&M \$/kW -yr & 3.8 & 7.25 \\
Variable O\&M \$/MWh & 1.9 & 2.2 \\
BESS total cost when installed at MV or LV with 0\% WT (14,477 AH), \$ & 79,729 & 76,049 \\
BESS total cost when installed at MV or LV with 10\% WT (13,999 AH), \$ & 77,066 & 93,509 \\
BESS total cost when distributed at LV with 0\% WT (25,852 AH), \$ & 142,366 & 135,795 \\
BESS total cost when distributed at LV with 10\% WT (17,717 AH), \$ & 97,570 & 93,066 \\
\hline
\end{tabular}

Original price was in Euro, $1 €=1.05 \$$ is used for unifying the cost in $\$$. 


\section{Assumptions:}

According to the average load calculation used in this research, the BESS is charging for $9 \mathrm{~h}$ and discharging for $15 \mathrm{~h}$. The BESS charging/discharging cycle is daily based; hence the number of life cycles is the number of life-days. The calculation is based on 15-year life of the transformer and batteries before replacement is required. For simplicity, the electricity price per $\mathrm{kWh}$ is assumed constant over the period of equipment life at $\$ 168 / \mathrm{MWh}$. The cost of wind power installation, maintenance and connection is not included in the calculation. Two types of battery technology $(\mathrm{NaS}, \mathrm{Li})$ have been used to explore the power loss savings achieved using BESS and investigate the cost of the BESS for the scenarios described above.

As shown in Figure 21, the savings over the life time of the proposed system are significant when the BESS is distributed at busbar levels: This mainly eliminates the losses in the distribution cables and will payback for the BESS total cost.

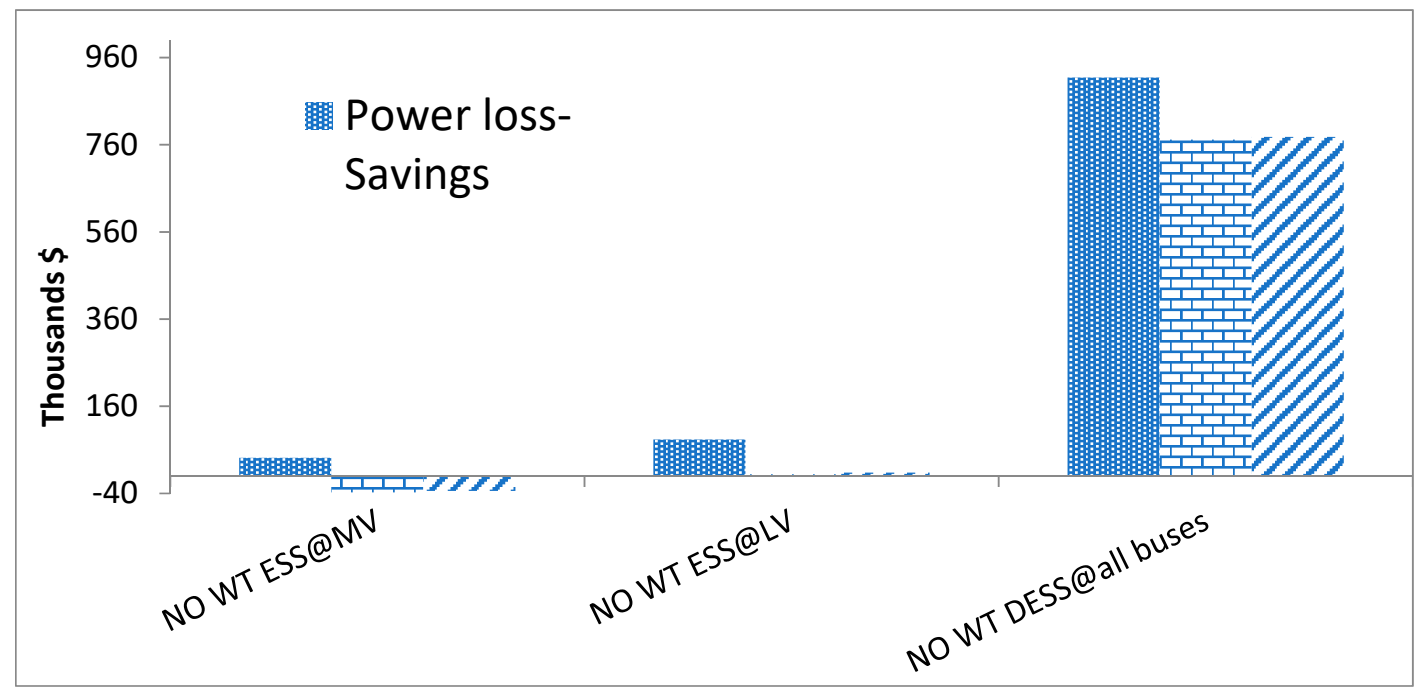

Figure 21. Achieved cost savings using BESS with no WT in the distribution network (DN).

In this study the authors considered the rate of discount of 3.5\% as estimated in [41], the present worth of an amount obtained annually for 15-years is calculated based on Equation (13) as follows:

$$
P=A \cdot \frac{(1+i)^{n}-1}{i \cdot(1+i)^{n}}
$$

where $n=15, i=0.035, A$ is the present value, $p$ is the present worth value, therefore, the savings are multiplied by 11.517 instead of 15 . This coefficient is applied to the calculation of the savings in energy losses in all studied scenarios and also to the maintenance and operation costs of the BESS, however flat rate of electricity price over the 15 -years is assumed.

Based on this economic consideration of the savings, all possible savings in the distribution transformer losses, transmission line losses and the distribution LV cables are summarised in Table 7.

Table 7. Savings of distribution transformer in a period of 15 years, \$168 / MWh · 15 Y.

\begin{tabular}{ccccc}
\hline & Savings in DT & Savings in TL & $\begin{array}{c}\text { Savings in D LV } \\
\text { Cables }\end{array}$ & $\begin{array}{c}\text { Total Power } \\
\text { Loss-Savings }\end{array}$ \\
\hline NO WT BESS@MV & 0 & 41,793 & 0 & 41,793 \\
NO WT BESS@LV & 41,977 & 41,793 & 0 & 83,771 \\
NOWT D-BESS@all buses & 41,977 & 41,793 & 830,101 & 913,872 \\
10\% WT@LV and BESS@MV & 29,616 & 68,944 & 0 & 98,559 \\
10\% WT@LV and BESS@LV & 69,247 & 68,944 & 0 & 138,190 \\
10\% DWT and BESS @LV & 69,247 & 68,944 & 587,183 & 725,373 \\
$10 \%$ DWT and D-BESS @same bus & 65,925 & 65,637 & $1,265,543$ & $1,397,105$ \\
\hline
\end{tabular}


As the Li batteries storage cost with grid integration converters are quite similar to the overall cost of NaS batteries, its attributed savings is promising in the near future due to sharp reduction in its cost per $\mathrm{kWh}$ over the past few years and expected to continue, it is expected to reach $\$ 100 / \mathrm{kWh}$. Issues like protection and hazard control of the Li batteries, which are main barriers for deployment on large scale, are not part of this research investigation but expected to be overcome.

As can be predicted from Figure 22, distributing WT's and BESS at the same busbar will lead to considerable savings, yet this will shift the responsibility and ownership of both WT and BESS to the individual customers. The use of Li batteries may lead to savings due to its price drop and investment in its mass production.

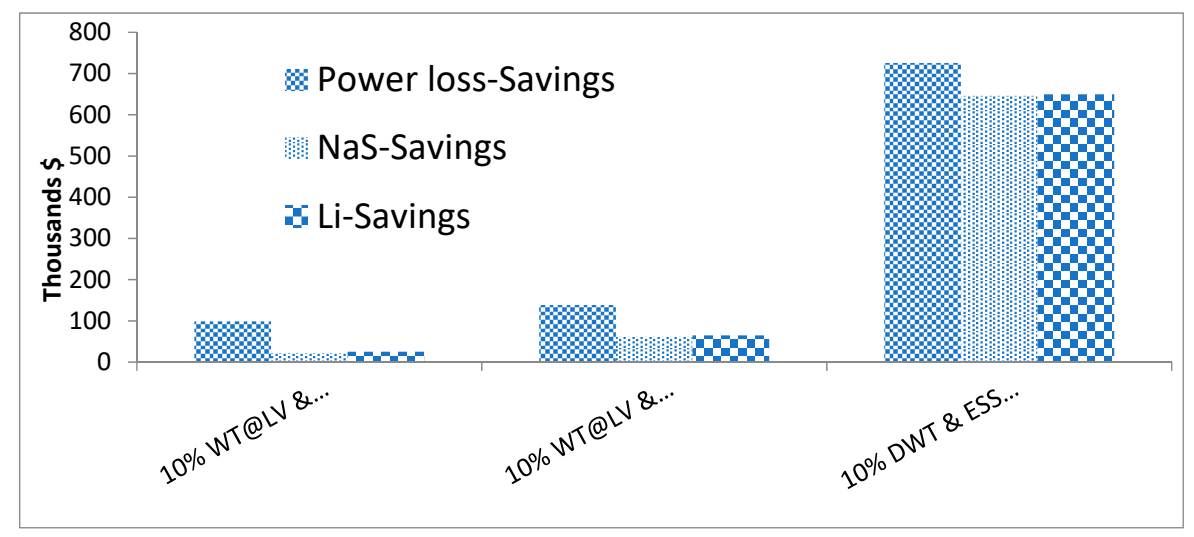

Figure 22. Achieved cost savings with $10 \%$ penetration of WT and BESS.

\subsection{Economic Evaluation of DT}

As was calculated in Section 5, the transformer loss of life for the $24 \mathrm{~h}$ period analyzed is $7.72 \mathrm{~h}$ in the base case and $0.47 \mathrm{~h}$ in the case of connecting the BESS at the LV side of the distribution transformer. According to those calculations, the life expectancy of the transformer solid-insulation would be multiplied by 16-fold and consequently, the "theoretical life" of the transformer, which is generally considered to be within 15 to 20 years [26], would be extended.

It is important to note that these calculations are only referred to as the thermal life of solid insulation, which is the main factor that determines the transformer remaining life. As the cellulosic insulation ages, it loses its mechanical properties and becomes weak and breakable which can give rise to different types of failures, such as short circuits, partial discharges or hot spots in the windings. If the solid insulation of a transformer is kept in good condition, the reliability of the equipment increases and its failure probability drops significantly. However, it must be noted that even transformers with non-aged solid insulation can suffer unexpected failures of external origin, or at other elements such as the core or bushings.

Different criteria can be applied for the estimation of the end of life of a transformer's cellulosic insulation [42], namely a 50\% loss of the tensile strength of the insulation, a $75 \%$ loss of the tensile strength of the insulation, a degree of polymerization of insulation $<200$, or a definition of the end of life according to the experience derived from transformer's functional life test data. Depending on the adopted criterion, the life expectancy of a transformer with dry insulation that operates at rated load (i.e., hottest spot temperature around $110{ }^{\circ} \mathrm{C}$ ) is estimated as $65,000 \mathrm{~h}$ (7.4 years), 135,000 $\mathrm{h}$ (15.4 years), $150,000 \mathrm{~h}$ (17.12 years) or 180,000 h (20.5 years) respectively [42]. Overloading a transformer or operating it with a high moisture content in the solid insulation, would shorten the expected life below these estimations. On the other hand, it is not unusual that transformers operate below their rated load (and thus with hottest spot temperatures below $110^{\circ} \mathrm{C}$ ) which would extend the life expectancy of the solid insulation to 30 years or more. It should be noted that, although in some cases transformers remain in service for more than 40 years, experience shows that after 30 years of service transformers are more likely to fail. 
For the economical evaluation of the transformer loss of life carried out in this work, it is assumed that the transformer under analysis is replaced after 15 years of service for the base case and after 30 years of service if the BESS is connected in the LV side of the system.

Considering a cost for a $500 \mathrm{kVA}$ transformer of 20,000\$, and an interest rate $3.5 \%$, as recommended in the UK Government Green book [41], the saving in transformer purchase if the BESS is installed could be estimated as $\$ 11,937$ in a 15 years period (i.e., present net value with one replacement is $\$ 31,937$ (Net cost of the system with one replacement after $n$ years $=$ cost for year $0+$ Cost for year $\left.0 /(1+\text { interest rate })^{n}\right)$ vs. $\$ 20,000$ if only one transformer is installed).

If the saving in power losses, as detailed in Table 7, and transformer life are aggregated for the different considered scenarios, the economic benefits of integrating BESS and renewables are very obvious. To calculate the saving in transformer losses, only the load losses were considered since the no-load losses are not influenced by the presence of BESS.

Finally, although it is not easy to quantify from the economic point of view, it must be added that the value of operating a transformer with a lower probability of failure is an important factor to consider. Reduction in customer complaints and in the economic penalties that result from repair and replacement must be taken into consideration.

\section{Conclusions}

This study has addressed the integration of energy storage systems and renewable energy sources into a distribution network. Various scenarios address the impact of bulk and/or distributed installation on the grid performance from the losses point of view. The storage capacity that is required to achieve maximum savings is identified.

It is clear from the simulation results that distributing the renewable source, WT's in this case, across the load busbars has a great effect on reducing the aggregated losses in the transmission line, transformer and distribution cables. However, from the storage capacity point of view, the bulk installation of the energy storage system at the low voltage side of the distribution transformer is the best solution as this led to a minimum rating of BESS installation. The study shows the benefit of extending the distribution transformer life cycle by adopting BESS at the same bus where wind turbines are installed. The researchers recommend investigating the impacts of other renewable sources that likely to be installed in the DN in the near future like PV and vehicle-to-grid (V2G), also to look into the impacts on the feeders of the DN at $33 \mathrm{kV}$.

Author Contributions: Conceptualization, M.E.A.F.; methodology, M.E.A F. and B.G.; software, M.E.A.F. and B.G.; validation, D.M.H. and B.G.; formal analysis, M.E.A.F.; investigation, M.E.A.F.; writing一original draft preparation, M.E.A.F.; writing-review and editing, M.E.A.F., B.G. and D.M.H.

Funding: This research received no external funding.

Acknowledgments: The author would like to thank TUVNEL for the collaboration and providing raw data for system under study.

Conflicts of Interest: The authors declare no conflict of interest.

\section{Appendix A}

Table A1. Cables datasheet.

\begin{tabular}{ccc}
\hline Cable Length & R-ohm/km/ph & X-ohm $/ \mathbf{k m} / \mathbf{p h}$ \\
\hline $100 \mathrm{~m}$ & 0.443 & 0.076 \\
$65 \mathrm{~m}$ & 0.443 & 0.076 \\
$37.5 \mathrm{~m}$ & 0.443 & 0.076 \\
$34 \mathrm{~m}$ & 0.2533 & 0.073 \\
$133.75 \mathrm{~m}$ & 0.2533 & 0.073 \\
$55 \mathrm{~m}$ & 0.1258 & 0.068 \\
$50 \mathrm{~m}$ & 0.1258 & 0.068 \\
$4 \mathrm{~km}$ & 0.32 & 0.075 \\
\hline
\end{tabular}


Table A2. Transformer datasheet.

\begin{tabular}{cccc}
\hline Size & Mounting & R-ohm & X-ohm \\
\hline $500 \mathrm{kVA}$ & Ground & 0.0051 & 0.0171 \\
\hline
\end{tabular}

\section{References}

1. IEC. Electrical Energy Storage, White Paper. Available online: https://www.iec.ch/whitepaper/energystorage/ (accessed on 29 July 2014).

2. Dunn, B.; Kamath, H.; Tarascon, J.-M. Electrical Energy Storage for the Grid: A Battery of Choices. Science 2011, 334, 928-935. [CrossRef] [PubMed]

3. Wadiaa, C.; Albertusc, P.; Srinivasand, V. Resource constraints on the battery energy storage potential for grid and transportation applications. J. Power Sources 2011, 196, 1593-1598. [CrossRef]

4. Vazquez, S.; Lukic, S.M.; Galvan, E.; Franquelo, L.G.; Carrasco, J.M. Energy Storage Systems for Transport and Grid Applications. IEEE Trans. Ind. Electron. 2010, 57, 3881-3895. [CrossRef]

5. Xu, Y.; Xie, L.; Singh, C. In Proceedings of the Optimal Scheduling and Operation of Load Aggregator with Electric Energy Storage in Power Markets. North American Power Symposium (NAPS), Arlington, TX, USA, 26-28 September 2010; pp. 1-7.

6. Naveen, G.; Kumar, B.P.; Sudheer, M.L. Demand side load levelling using distributed micro energy and storage systems with the establishment of micro grids. In Proceedings of the Innovative Smart Grid Technologies-Asia, Bangalore, India, 10-13 November 2013; pp. 1-6.

7. Xu, H.; Topcu, U.; Low, S.H.; Clarke, C.R.; Chandy, K.M. Load-shedding probabilities with hybrid renewable power generation and energy storage. In Proceedings of the Forty-Eighth Annual Allerton Conference Allerton House, Allerton, IL, USA, 29 September-1 October 2010; pp. 233-239.

8. Van de Ven, P.M.; Hegde, N.; Massoulie, L.; Salonidis, T. Optimal Control of End-User Energy Storage. IEEE Trans. Smart Grid 2013, 4, 789-797. [CrossRef]

9. Choi, S.; Min, S. Optimal Scheduling and Operation of the ESS for Prosumer Market Environment in Grid-Connected Industrial Complex. IEEE Trans. Ind. Appl. 2018, 54, 1949-1957. [CrossRef]

10. Shim, J.W.; Verbič, G.; Zhang, N.; Hur, K. Harmonious Integration of Faster-Acting Energy Storage Systems Into Frequency Control Reserves in Power Grid With High Renewable Generation. IEEE Trans. Power Syst. 2018, 33, 6193-6205. [CrossRef]

11. Torres, L.M.A.; Lopes, L.A.; Morán, T.; Espinoza, C.J.R. Self-Tuning Virtual Synchronous Machine: A Control Strategy for Energy Storage Systems to Support Dynamic Frequency Control. IEEE Trans. Energy Convers. 2014, 29, 833-840. [CrossRef]

12. Tang, X.; Hu, X.; Li, N.; Deng, W.; Zhang, G. A Novel Frequency and Voltage Control Method for Islanded Microgrid Based on Multienergy Storages. IEEE Trans. Smart Grid 2016, 7, 410-419. [CrossRef]

13. Yan, N.; Zhang, B.; Li, W.; Ma, S. Hybrid Energy Storage Capacity Allocation Method for Active Distribution Network Considering Demand Side Response. IEEE Trans. Appl. Supercond. 2019, 29, 1-4. [CrossRef]

14. Mohd, A.; Ortjohann, E.; Schmelter, A.; Hamsic, N.; Morton, D. Challenges in integrating distributed Energy storage systems into future smart grid. In Proceedings of the IEEE International Symposium on Industrial Electronics, Cambridge, UK, 30 June-2 July 2008; pp. 1627-1632.

15. Nourai, A.; Kogan, V.I.; Schafer, C.M. Load Leveling Reduces T\&D Line Losses. IEEE Trans. Power Deliv. 2008, 23, 2168-2173.

16. Saboori, H.; Abdi, H. Application of a grid scale energy storage system to reduce distribution network losses. In Proceedings of the 18th Conference on Electrical Power Distribution Networks (EPDC), Kermanshah, Iran, 30 April-1 May 2013; pp. 1-5.

17. Mittal, R.; Sandhu, K.S.; Jain, D.K. Battery energy storage systems for variable speed driven PMSG for wind energy conversion systems. Int. J. Innov. Manag. Technol. 2010, 1, 300-304.

18. Kim, K.; Song, K.; Joo, S.; Lee, Y.; Kim, J. Multiobjective distributed generation placement using fuzzy goal programming with genetic algorithm. Eur. Trans. Electr. Power 2008, 18, 217-230. [CrossRef]

19. Bustos, C.; Sauma, E.; de la Torre, S.; Aguado, J.A.; Contreras, J.; Pozo, D. Energy storage and transmission expansion planning: Substitutes or complements? IET Gener. Transm. Distrib. 2018, 12, 1738-1746. [CrossRef] 
20. Nick, M.; Cherkaoui, R.; Paolone, M. Optimal Planning of Distributed Energy Storage Systems in Active Distribution Networks Embedding Grid Reconfiguration. IEEE Trans. Power Syst. 2018, 33, 1577-1590. [CrossRef]

21. Lei, J.; Gong, Q.; Liu, J.; Qiao, H.; Wang, B. Optimal allocation of a VRB energy storage system for wind power applications considering the dynamic efficiency and life of VRB in active distribution networks. IET Renew. Power Gener. 2019, 13, 563-571. [CrossRef]

22. Xiang, Y.; Han, W.; Zhang, J.; Liu, J.; Liu, Y. Optimal Sizing of Energy Storage System in Active Distribution Networks Using Fourier-Legendre Series Based State of Energy Function. IEEE Trans. Power Syst. 2018, 33, 2313-2315. [CrossRef]

23. Zheng, Y.; Zhao, J.; Song, Y.; Luo, F.; Meng, K.; Qiu, J.; Hill, D.J. Optimal Operation of Battery Energy Storage System Considering Distribution System Uncertainty. IEEE Trans. Sustain. Energy 2018, 9, 1051-1060. [CrossRef]

24. Munksgaard, J.; Morthorst, P.E. Wind power in the Danish liberalised power market-Policy measures, price impact and investor incentives. Energy Policy 2008, 36, 3940-3947. [CrossRef]

25. Nguyen, M.Y.; Nguyen, D.H.; Yoon, Y.T. Anew battery approach to wind generation system in frequency control market. J. Electr. Eng. Technol. 2013, 8, 742-749. [CrossRef]

26. Awad, A.S.A.; Al-Fouly, T.H.M.; Salama, M.A. Optimal ESS Allocation for Load Management Application. IEEE Trans. Power Syst. 2015, 30, 327-336. [CrossRef]

27. United Kingdom Generic Distribution System (UKGDS). Available online: www.SEDG.ac.uk (accessed on 3 October 2018).

28. E.ON Central Networks. Network Design Manual. Available online: https://www.yumpu.com/en/document/ view/8953808/network-design-manual-eon-uk (accessed on 18 April 2014).

29. MacDonald, M. System Integration of Additional Micro-Generation; SIAM, (DG/CG, 00028/REP); DTI: London, UK, 2004. accessed on 2 May 2019.

30. Board, I. IEEE Guide for Loading Mineral-Oil-Immersed Transformers. IEEE Std. C. 1995, 57, 1-112.

31. IEC. Guide to Loading of Oil Immersed Power Transformers. 1991. Available online: https://www.saiglobal.com/ pdftemp/previews/osh/iec/iec60000/60300/iec60354\%7Bed2.0\%7Den_d.img.pdf (accessed on 2 February 2018).

32. Nordman, H.; Rafsback, N.; Susa, D. Temperature responses to step changes in the load current of power transformers. IEEE Trans. Power Deliv. 2003, 18, 1110-1117. [CrossRef]

33. NGK Insulators Ltd. NGK Receiving Orders. Available online: www.ngk.co.jp/english/news/2015/0622.html (accessed on 2 August 2016).

34. Liao, Q.; Sun, B.; Liu, Y.; Sun, J.; Zhou, G. A techno-economic analysis on NaS battery energy storage system supporting peak shaving. Int. J. Energy Res. 2016, 40, 241-247. [CrossRef]

35. USA Department of Energy, Grid Energy Storage Report. Available online: http://www.energystorageexchange. org/projects (accessed on 2 August 2016).

36. Zakeri, B.; Syri, S. Electrical energy storage systems: A comparative life cycle cost analysis. Renew. Sustain. Energy Rev. 2015, 42, 569-596. [CrossRef]

37. Bradbury, K.; Pratson, L.; Patiño-Echeverri, D. Economic viability of energy storage systems based on price arbitrage potential in real-time USA electricity markets. Appl. Energy 2014, 114, 512-519. [CrossRef]

38. Ciez, R.E.; Whitacre, J.F. Comparative techno-economic analysis of hybrid micro-grid systems utilizing different battery types. Energy Convers. Manag. 2016, 112, 435-444. [CrossRef]

39. Dufo-Lopez, R.; Bernal-Agustin, J.L. Techno-economic analysis of grid-connected battery storage. Energy Convers. Manag. 2015, 91, 394-404. [CrossRef]

40. Hannan, M.A.; Hoque, M.M.; Hussain, A.; Yusof, Y.; Ker, P.J. State-of-the-art and energy management system of lithium-ion batteries in electric vehicle applications: Issues and recommendations. IEEE Access 2018, 6, 19362-19378. [CrossRef]

41. Available online: https://assets.publishing.service.gov.uk/government/uploads/system/uploads/attachment_ data/file/685903/The_Green_Book.pdf (accessed on 10 February 2019).

42. Del Vecchio, R.M.; Del Vecchio, R.; Poulin, B.; Feghali, P.T.; Shah, D.M.; Ahuja, R. Transformer Design Principles, 3rd ed.; CRC Press: Boca Raton, FL, USA, 2017.

(C) 2019 by the authors. Licensee MDPI, Basel, Switzerland. This article is an open access article distributed under the terms and conditions of the Creative Commons Attribution (CC BY) license (http://creativecommons.org/licenses/by/4.0/). 